\title{
Seasonal sea level extremes in the Mediterranean Sea and at the Atlantic European coasts
}

\author{
M. N. Tsimplis and A. G. P. Shaw \\ National Oceanography Centre, Southampton, SO14 3ZH, UK \\ Received: 26 January 2010 - Revised: 2 May 2010 - Accepted: 5 June 2010 - Published: 9 July 2010
}

\begin{abstract}
Hourly sea level data from tide gauges and a barotropic model are used to explore the spatial and temporal variability of sea level extremes in the Mediterranean Sea and the Atlantic coasts of the Iberian peninsula on seasonal time scales. Significant spatial variability is identified in the observations in all seasons. The Atlantic stations show larger extreme values than the Mediterranean Sea primarily due to the tidal signal. When the tidal signal is removed most stations have maximum values of less than $90 \mathrm{~cm}$ occurring in winter or autumn. The maxima in spring and summer are less than $60 \mathrm{~cm}$ in most stations. The wind and atmospheric forcing contributes about $50 \mathrm{~cm}$ in the winter and between $20-40 \mathrm{~cm}$ in the other seasons. In the western Mediterranean the observed extreme values are less than $50 \mathrm{~cm}$, except near the Strait of Gibraltar. Direct atmospheric forcing contributes significantly to sea level extremes. Maximum sea level values due to atmospheric forcing reach in some stations $45 \mathrm{~cm}$ during the winter. During the summer the contribution of the direct atmospheric forcing is between $10-20 \mathrm{~cm}$. The Adriatic Sea shows a resonant behaviour with maximum extreme observed sea level values around $200 \mathrm{~cm}$ found at the northern part. Trends in the $99.9 \%$ percentiles are present in several areas, however most of them are removed when the $50 \%$ percentile is subtracted indicating that changes in the extremes are in line with mean sea level change. The North Atlantic Oscillation and the Mediterranean Oscillation Index are well correlated with the changes in the $99.9 \%$ winter values in the Atlantic, western Mediterranean and the Adriatic stations. The correlation of the NAO and the MOI indices in the Atlantic and western Mediterranean is significant in the autumn too. The correlations between the NAO
\end{abstract}

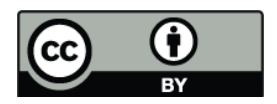

Correspondence to: A. G. P. Shaw (agps@noc.soton.ac.uk) and MOI index and the changes in the sea level extremes become insignificant when the 50\% percentile is removed indicating again that changes in extremes have been dominated by changes in the mean sea level.

\section{Introduction}

Studies on extreme sea levels are important for two reasons. First, in the form of return periods they provide useful parameters for the design of coastal planning. Second, changes in the extreme distributions can be used as indicators of changes in the forcing characteristics and particularly linked with changes in storminess at a location.

Tsunamis, tidal oscillations, wind waves, storm surges as well as steric effects and oceanic circulation all contribute to the generation of the extreme sea level values observed. Tsunamis are by far the more catastrophic sea level extreme events. However, they are usually omitted from extreme sea level studies as their observation is, in most locations, too sparse to permit any statistical analysis to be performed. Wind waves are also usually excluded from the analysis of sea level measurements either by physical filtering or electronically by averaging or filtering the sea level signal. Despite the convenience of these well established methods one has to accept that overtopping of sea defenses as well as coastal erosion and general geomorphological changes are certainly linked if not dominated by waves rather than the low-passed mean sea level signal. Changes in mean sea level also change the baseline for the waves. It is also important to note that wave heights have been known to change as well as wind directions in response to regional climate changes (e.g. Tsimplis et al., 2005a; Wolf and Woolf, 2006).

Published by Copernicus Publications on behalf of the European Geosciences Union. 
Tides, in spite of their predictability may also change as a response of changes to mean sea level rise thus providing a contribution to future extreme sea levels. On the basis of modeling studies the changes in the tidal signal with means sea level rise are considered to be small in most areas. Thus when $0.5 \mathrm{~m}$ of sea level rise was imposed in a North Sea model changes in the tidal signal of about $\pm 10 \%$ of the mean sea level change (less than $5 \mathrm{~cm}$, were found. In most parts the changes in the tidal signal were $\pm 1-2 \mathrm{~cm}$ (R. Flather, personal communication). Similarly a sensitivity study for the Adriatic Sea indicates that a sea level rise of $1 \mathrm{~m}$ will result to less than $\pm 10 \%$ of change in the tidal constituents (Lionello et al., 2005). These actual changes were found to be around $\pm 1-2 \mathrm{~cm}$. Of course these studies do not exclude the possibility of significant effects in areas where the mean sea level changes will move the oscillations closer to resonant modes. For example, Weisse and Von Storch (2010) suggest larger changes at the estuary and upstream in the river Elbe with the mean tidal range increasing by $17 \mathrm{~cm}$ for a $1 \mathrm{~m}$ mean sea level rise.

Other local phenomena, like atmospherically generated waves in the tsunami frequency band, sometimes called "meteorological-tsunamis", as well as basin oscillations may also be important in determining the generation of extreme sea levels under particular circumstances (Vilibic, 2005; Monserrat et al., 2006; Vilibic and Sepic, 2009). Storm surges and their combination with tides are by far the more important forcing parameters for the generation of extremes sea levels. Under climate change scenarios sea level rise is expected in many parts of the world. In addition, changes in storminess could lead to changes in sea level extremes in addition to mean sea level rise thus exacerbating the risks involved. Whether changes in storminess are happening is debatable (see for example Trenberth and Fassulo, 2007; Trenberth et al., 2007, and references therein). The study of extreme sea levels can provide indirect evidence for such changes. Presently studies on recent sea level extremes globally and regionally do not identify any changes in storminess. In addition changes in extreme sea level are found to be consistent with changes in mean sea level (Woodworth and Blackman, 2004; Marcos et al., 2009). Shifts to meteorological patterns and particularly storm tracks are likely to cause local changes in the distribution of extremes even if storminess may not change regionally. This may mean increases or decreases of extremes in particular regions as well as potential changes in seasonality.

The coasts of southern Europe consist of two distinctly different tidal regimes. The tidal signal at the Atlantic coasts exceeds $2 \mathrm{~m}$ during spring tides while in most areas within the Mediterranean Sea the tidal signal is an order of magnitude smaller with the important exceptions of the Adriatic Sea and the Gulf of Gabes (Tsimplis et al., 1995). Thus, in most of the Mediterranean basin sea level extremes are mainly caused by storm surges rather than by the combination of tides and surges (Marcos et al., 2009).
The Northern Adriatic Sea is the area in the Mediterranean where extremes are most studied because of the presence of several historic cities, the prominent of which is Venice (Raicich, 2003; Pirazzoli and Tomasin, 2002; Pirazzoli and Tomasin, 2008). In the Aegean and Ionian Seas, Tsimplis and Blackman (1997) analyzed the available tide gauge data and estimated return periods of extreme sea levels over a period of eight years. Marcos et al. (2009) provide an up to date review and analysis of the extreme sea level in this region. Ullmann and Moron (2008) and Ullmann et al. (2008) have examined the relationship between the observed sea surges and the weather regimes in the Gulf of Lions (NW Mediterranean).

Changes in the extremes are even less researched than the mapping of extremes. For Trieste, in the Adriatic, Raicich (2003) showed a reduction in the strong positive and negative surges at Trieste over the period 1939-2001. For Venice Pirazzoli and Tomasin (2002) have found that the frequency and intensity of floods had increased in the recent past. These results are not necessarily conflicting for two reasons. First because strong surges are relatively rare events while floods may include moderate events and, second, surges are referred to a certain mean sea level, while floods are relative to a fixed reference.

Marcos et al. (2009) found significant trends in the extremes of some of the tide gauge records they analysed. Their study covered the Mediterranean as well as coastal stations at the east Atlantic coasts. However the changes in extremes found were consistent with the mean sea level changes which are described in several studies (for example see Cazenave et al., 2001, 2002; Fenoglio-Marc, 2002; Marcos and Tsimplis, 2008). Pirazzoli and Tomasin (2008) also analysed several Mediterranean stations by using various methods. The analysis of Marcos et al. (2009) and Pirazzoli and Tomasin (2008) are based on hourly sea level observations. Tsimplis et al. (2009) demonstrate that the use of data sampled at higher frequency result in identification of higher extreme values and return periods. However, long time series of data sampled at frequencies higher than $1 \mathrm{~h}$ are not yet available, thus in this study we will use hourly values.

In this study we extend the work of Marcos et al. (2009) by producing estimates of the changes in the seasonal sea level extremes. Understanding the distribution of extremes seasonally and identifying their variability in time is important for two reasons. First, in order to understand the changes in forcing at seasonal scales and second in order to identify potentially dangerous situations in vulnerable areas.

\section{Data and methodology}

The data and quality checks are the same used in Marcos et al. (2009). A brief outline is provided but the reader is advised to refer to that publication for details. 
Table 1. The geographical coordinates and the period of operation of the tide gauge stations used in this study. Some tide gauge records were split (i.e. named as I, II, etc.) due to inconsistencies in their mean sea level indicating benchmark shifts (see Marcos et al., 2009).

\begin{tabular}{|c|c|c|c|c|c|c|c|c|c|c|c|}
\hline$\frac{\text { No. }}{1}$ & $\begin{array}{l}\text { Station name } \\
\text { Alexandropoulis }\end{array}$ & \multicolumn{2}{|c|}{ Location } & \multicolumn{2}{|c|}{ Period } & $\frac{\text { No. }}{47}$ & $\begin{array}{l}\text { Station name } \\
\text { Leros }\end{array}$ & \multicolumn{2}{|c|}{ Location } & \multicolumn{2}{|c|}{ Period } \\
\hline 2 & Alexandropoulis_2 & & & 2002 & 2002 & 48 & Livorno_I & $43.55 \mathrm{~N}$ & $10.30 \mathrm{E}$ & 1998 & 2006 \\
\hline 4 & Ancona_I & $43.63 \mathrm{~N}$ & $13.50 \mathrm{E}$ & 1991 & 2006 & 50 & Livorno_III & & & 1972 & 1981 \\
\hline 5 & Ancona_II & & & 1986 & 1988 & 51 & Malaga & $36.71 \mathrm{~N}$ & $4.41 \mathrm{~W}$ & 1992 & 2004 \\
\hline 6 & Barcelona & $41.35 \mathrm{~N}$ & $2.16 \mathrm{E}$ & 1992 & 2004 & 52 & Marseille & $43.12 \mathrm{~N}$ & $5.35 \mathrm{E}$ & 1985 & 2003 \\
\hline 9 & Antalya_III & & & 1998 & 2004 & 55 & Napoli_III & & & 1986 & 1990 \\
\hline 10 & Bari & $41.14 \mathrm{~N}$ & $16.45 \mathrm{E}$ & 1998 & 2006 & 56 & North_Halkis & $38.47 \mathrm{~N}$ & $23.6 \mathrm{E}$ & 1982 & 1988 \\
\hline 11 & Bilbao & $43.30 \mathrm{~N}$ & $0.93 \mathrm{~W}$ & 1992 & 2004 & 57 & Ortona & $42.36 \mathrm{~N}$ & $14.42 \mathrm{E}$ & 1997 & 2006 \\
\hline 12 & Cagliari_I & $39.21 \mathrm{~N}$ & $9.12 \mathrm{E}$ & 1992 & 2006 & 58 & Otranto & $40.15 \mathrm{~N}$ & $18.5 \mathrm{E}$ & 1987 & 2006 \\
\hline 13 & Cagliari_II & & & 1986 & 1991 & 59 & Palermo & $38.12 \mathrm{~N}$ & $13.52 \mathrm{E}$ & 1998 & 2006 \\
\hline 18 & Catania_I & $37.52 \mathrm{~N}$ & $15.08 \mathrm{E}$ & 1998 & 2006 & 64 & Posidonia & $37.95 \mathrm{~N}$ & $22.95 \mathrm{E}$ & 1982 & 1988 \\
\hline 19 & Catania_II & & & 1992 & 1997 & 65 & Porto_Torres_I & $40.84 \mathrm{~N}$ & $8.40 \mathrm{E}$ & 1995 & 2006 \\
\hline 20 & Catania_III & & & 1971 & 1981 & 66 & Porto_Torres_II & & & 1986 & 1990 \\
\hline 21 & Ceuta_2 & $35.67 \mathrm{~N}$ & $5.32 \mathrm{~W}$ & 1970 & 2004 & 67 & Preveza & $38.93 \mathrm{~N}$ & $20.77 \mathrm{E}$ & 1982 & 1988 \\
\hline 22 & Chios & $38.33 \mathrm{~N}$ & $26.13 \mathrm{E}$ & 1982 & 1988 & 68 & Rafina & $38.02 \mathrm{~N}$ & $24.00 \mathrm{E}$ & 1984 & 1988 \\
\hline 23 & Chios_2 & $38.33 \mathrm{~N}$ & $26.13 \mathrm{E}$ & 2002 & 2005 & 69 & Ravenna & $44.50 \mathrm{~N}$ & $12.28 \mathrm{E}$ & 1986 & 2006 \\
\hline 24 & Civitavecchia_I & $42.09 \mathrm{~N}$ & $11.12 \mathrm{E}$ & 1992 & 2006 & 70 & Reggio_Calabria & $38.12 \mathrm{~N}$ & $15.65 \mathrm{E}$ & 1998 & 2006 \\
\hline 25 & Civitavecchia_II & & & 1986 & 1989 & 71 & Rodos & $36.4 \mathrm{~N}$ & $28.08 \mathrm{E}$ & 1982 & 1988 \\
\hline 26 & Coruna & $43.17 \mathrm{~N}$ & $8.42 \mathrm{~W}$ & 1943 & 2000 & 72 & Rovinj & $45.08 \mathrm{~N}$ & $13.63 \mathrm{E}$ & 1959 & 2001 \\
\hline 27 & Coruna_2 & $43.17 \mathrm{~N}$ & $8.42 \mathrm{~W}$ & 1992 & 2004 & 73 & Salerno & $40.68 \mathrm{~N}$ & $14.75 \mathrm{E}$ & 1999 & 2006 \\
\hline 28 & Crotone_I & $39.08 \mathrm{~N}$ & $17.14 \mathrm{E}$ & 1999 & 2006 & 74 & Santander & $43.43 \mathrm{~N}$ & $3.82 \mathrm{~W}$ & 1943 & 2000 \\
\hline 36 & Imperia_I & $43.88 \mathrm{~N}$ & $8.02 \mathrm{E}$ & 1998 & 2006 & 82 & Thessaloniki & $40.52 \mathrm{~N}$ & $22.97 \mathrm{E}$ & 1982 & 1988 \\
\hline 37 & Imperia_II & & & 1992 & 1994 & 83 & Toulon & $43.12 \mathrm{~N}$ & $5.92 \mathrm{E}$ & 1961 & 2003 \\
\hline 38 & Imperia_III & & & 1986 & 1986 & 84 & Trieste & $45.65 \mathrm{~N}$ & $13.76 \mathrm{E}$ & 1939 & 2005 \\
\hline 39 & Kalamata & $37.07 \mathrm{~N}$ & $22.02 \mathrm{E}$ & 1982 & 1988 & 85 & Valencia & $39.45 \mathrm{~N}$ & $0.32 \mathrm{~W}$ & 1992 & 2004 \\
\hline 40 & Katakolon & $37.63 \mathrm{~N}$ & $21.32 \mathrm{E}$ & 1982 & 1988 & 86 & Venezia_Salute & $45.42 \mathrm{~N}$ & $12.42 \mathrm{E}$ & 1983 & 2005 \\
\hline 41 & Kavalla & $40.98 \mathrm{~N}$ & $24.41 \mathrm{E}$ & 1982 & 1985 & 87 & Vieste_I & $41.89 \mathrm{~N}$ & $16.18 \mathrm{E}$ & 1998 & 2006 \\
\hline 42 & Koper & $45.55 \mathrm{~N}$ & $13.73 \mathrm{E}$ & 1962 & 1999 & 88 & Vieste_II & & & 1990 & 1992 \\
\hline 43 & Lagos & $37.10 \mathrm{~N}$ & $8.67 \mathrm{~W}$ & 1985 & 1999 & 89 & Vigo & $43.22 \mathrm{~N}$ & $8.63 \mathrm{~W}$ & 1943 & 2000 \\
\hline 44 & Lampedusa & $35.48 \mathrm{~N}$ & $12.62 \mathrm{E}$ & 1998 & 2006 & 90 & Vigo_2 & & & 1992 & 2004 \\
\hline 45 & Lefkas & $38.84 \mathrm{~N}$ & $20.71 \mathrm{E}$ & 1982 & 1988 & 91 & Villagarcia & $42.58 \mathrm{~N}$ & $8.67 \mathrm{~W}$ & 1997 & 2004 \\
\hline 46 & Lefkas_2 & $38.84 \mathrm{~N}$ & $20.71 \mathrm{E}$ & 2002 & 2003 & 92 & Zadar & $44.12 \mathrm{~N}$ & $15.24 \mathrm{E}$ & 1993 & 2001 \\
\hline
\end{tabular}

\subsection{Sea level observations}

Hourly values from seventy three records covering the Mediterranean Sea and the Atlantic Iberian coasts have been used in the analysis (Fig. 1 and Table 1). The time series have been made available through the ESEAS website (www.eseas.org) and the web sites of various national services. The records span different time periods (Fig. 2), from 

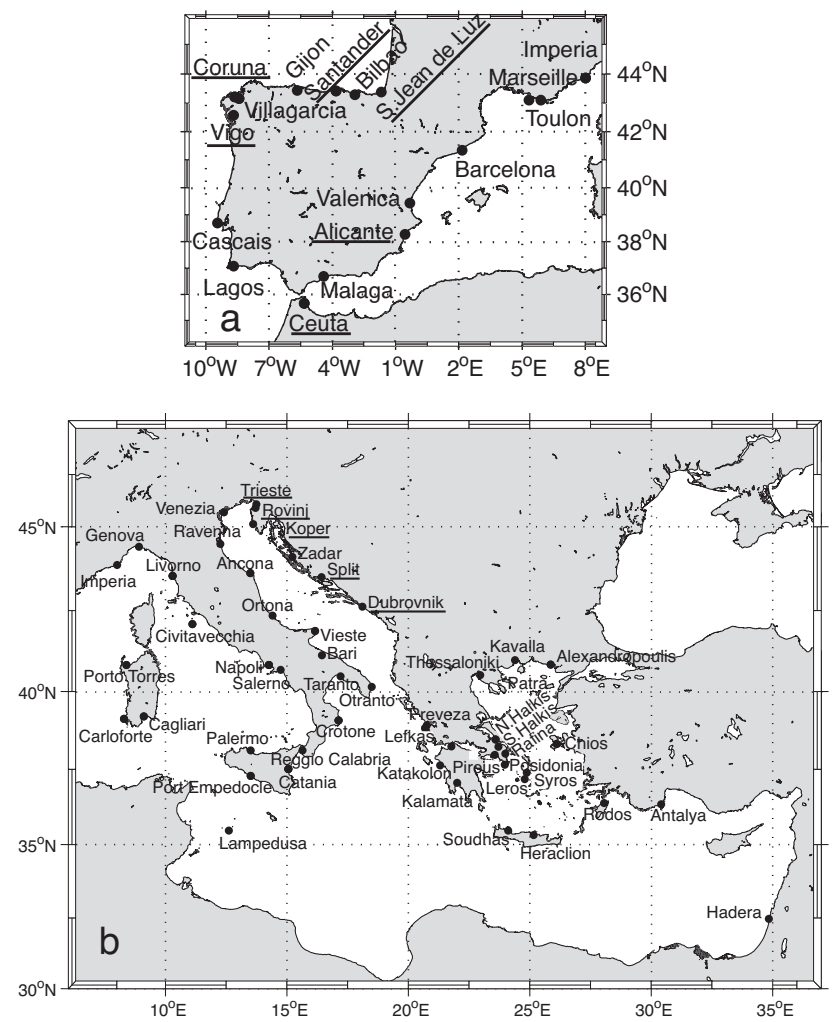

Fig. 1. The location of the tide gauges used in this study. The geographical coordinates of the stations are given in Table 1. The underlined tide gauge stations are used in the analysis of the time series of percentiles.

few months to 68 years, and were found to be of varying quality. Extensive quality control was undertaken by Marcos et al. (2009). However further tests were run for this study in order to ensure the validity of extremes for all seasons. The tides were estimated and removed from the records on a yearly basis. Tidal constituents with a signal-to-noise ratio equal or larger than three were fitted to the time series by harmonic analysis using the standard program $t$-tide (Pawlowicz et al., 2002). The tidal record, built as the addition of the significant tidal components, has been used as a tool to identify temporal drifts in the original sea level observations. Where time shifts were identified the observed time series were retained for the analysis of extremes in observations but the segments were the time shifts were noted were rejected from the analysis of the tidal residuals.

\subsection{Modelled sea level data}

The meteorological contribution to sea level has been quantified using the output of a barotropic oceanographic model. In the framework of the HIPOCAS (Hindcast of Dynamic Processes of the Ocean and Coastal Areas of Europe) project, atmospheric pressure and wind fields were produced by a dynamical downscaling of the reanalysis of NCEP/NCAR for the period 1958-2001 (García-Sotillo et al., 2005). These fields were used to force a barotropic version of the HAMSOM (Hamburg Shelf Circulation Model) model covering the Mediterranean Sea and the Eastern Atlantic coast, with a spatial resolution of $1 / 4^{\circ} \times 1 / 6^{\circ}$. The output was thus a consistent data set of 44 years of sea level hourly data (Ratsimandresy et al., 2008).

For each tide gauge station, data from the closest point of the hindcast grid has been subtracted from the observations for the period covered by the model data (19582001). The usefulness of this data set in reproducing the meteorologically-induced mean sea level has been proved in previous works (Tsimplis et al., 2005b; Gomis et al., 2006). The model is successful in reproducing changes in mean sea level but in general it underestimates the extremes.

The barotropic model is a better approximation of the direct atmospheric forcing than the standard inverse barometer correction in most places of the Mediterranean Sea and for high frequencies (Pascual et al., 2008). The inverse barometer correction assumes $1 \mathrm{~cm}$ of sea level increase(decrease) for 1 mbar reduction (increase) of local atmospheric pressure but it has been shown not to hold in the semi-enclosed seas and in particular in the Mediterranean. (e.g. Garrett and Majaess, 1984).

\subsection{Methodology}

We assess changes in extreme sea level by determining changes in percentiles. The method is non parametric and only involves ranking the observations and looking at the value that correspond to a particular percentile.

The median corresponds to the 50th percentile and has been taken to be approximately the same as the mean value (Woodworth and Blackman, 2002, 2004). The case may be, for particular years, that the largest values do not correspond to extremes. This however is not a problem for the percentiles method which are used here diagnostically for the existence of trends and not for return periods. We have calculated the percentiles on the basis of the available measurements ignoring the gaps in the time series. However gaps can be important in the estimation of percentiles either because an extreme is missed or because they occur in a particular period during which the mean sea level is high or low, thus affecting the estimation of the upper percentiles.

Percentiles are calculated for four seasons split as winter (December-March); spring (April-May); summer (JuneSeptember); and autumn (October-November). Trends for each season and the annual values are calculated for the $99.9 \%, 99 \% 95 \%, 90 \%$ and $50 \%$ percentiles. Here we report the results for $99.9 \%, 50 \%$ and $99.9 \%-50 \%$ values. The 99.9\% corresponds to the highest value for the transitional seasons and to the top 3 values for the winter and summer that cover 4 months.

We also distinguish between observed extremes and extremes derived after the subtraction of tides (tidal residuals). 


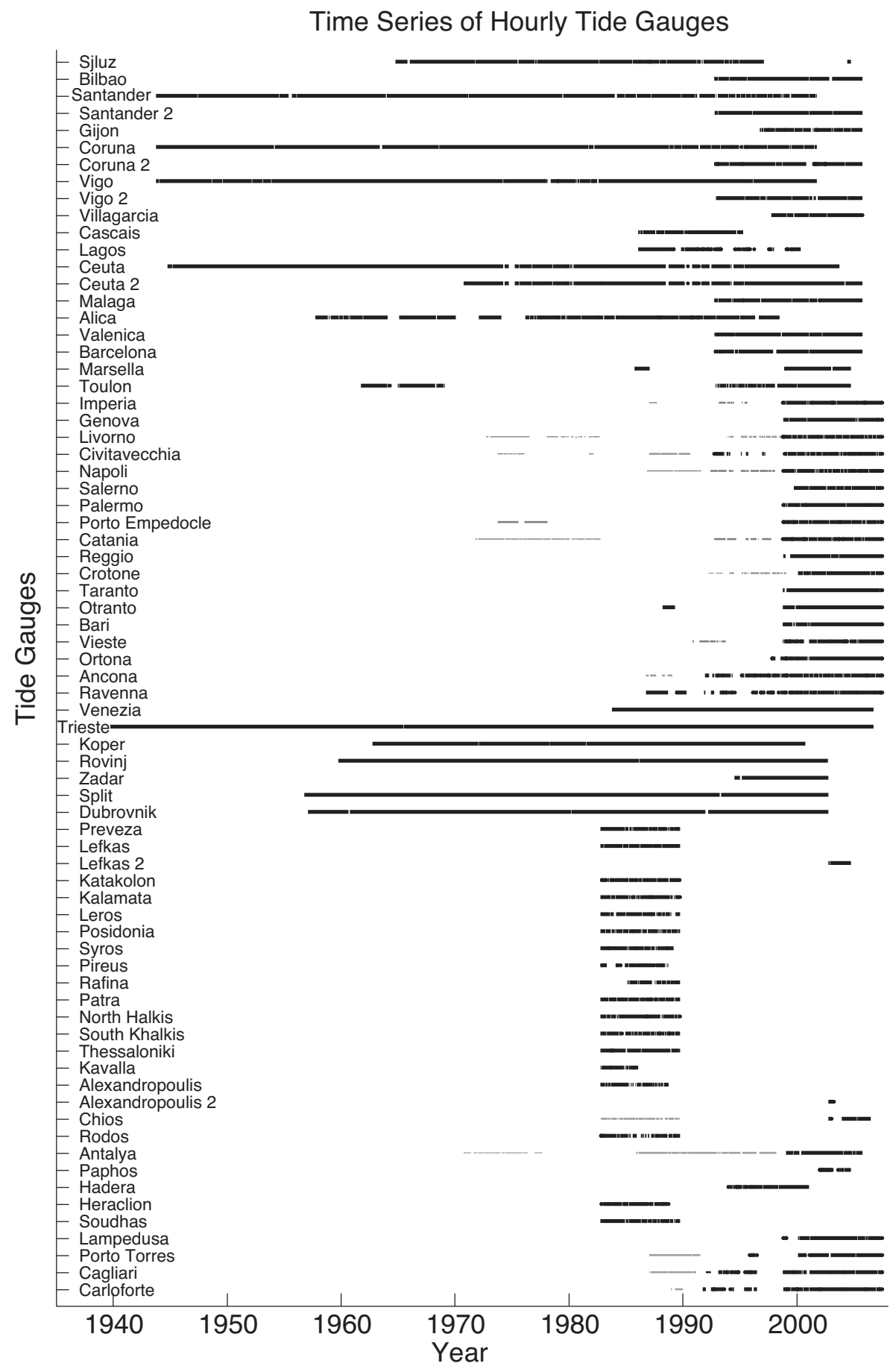

Fig. 2. Available hourly tide gauge observations. The thin lines indicate datum shifts within the time series records and consequently the record was split into more than one sub-records.

The latter are selected afresh after the tidal signal has been subtracted from the record. We also discuss extremes in the modelled sea level data and extremes for atmospherically corrected sea level values produced by subtracting the model values from the tidal residuals.
The interpretation of trends in sea level extremes is far from easy. The largest extreme values, if they happen near the beginning or the end of the record may determine the trend of the percentiles even where a robust method of estimating trends is employed. To test the significance of the trends we successively omitted one extreme value and 


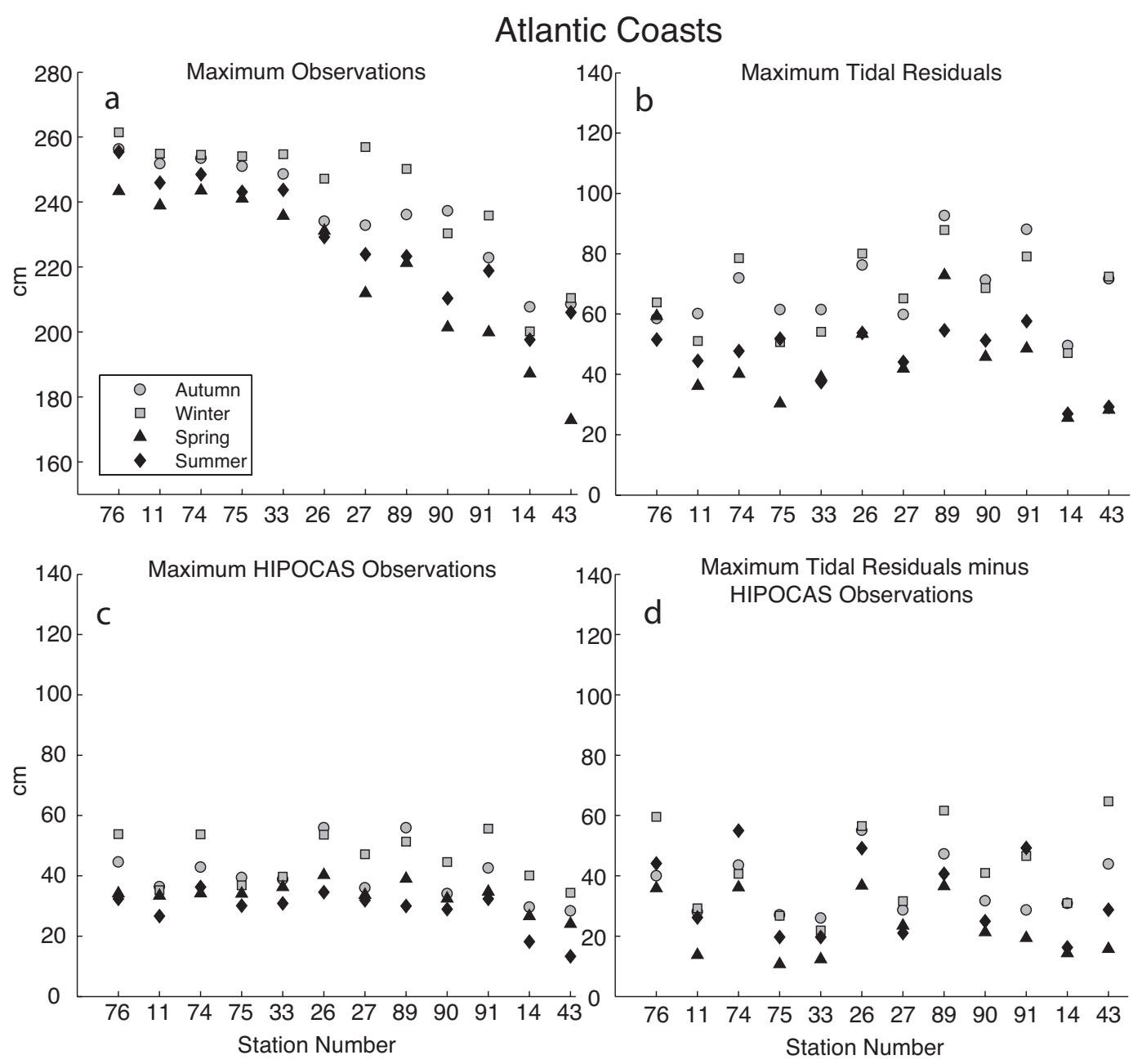

Fig. 3. Maximum seasonal values in the Atlantic coasts. Observations (a), tidal residuals (b), model (c) and tidal residual minus model values (d) for each season. The $\mathrm{x}$-axis corresponds to the station number.

estimated the trends. Other methodologies exist for the estimation of trends in extremes. For example Katz and Brown (1992) have used a slope in a Generalised Extreme Value (GEV) distribution to assess trends and Barbosa (2008) has used quantile regression. We have used the GEV with a slope (Coles, 2001) to confirm the results obtained through the percentile method. The trends obtained by the two methods were in agreement within their error bars. The percentile method was found to be more conservative in the sense that it produced fewer statistically significant trends than the GEV with a slope method.

The aim of our study is to describe the regional patterns of seasonal extremes and identify regional patterns of change in extreme. We start with a description of the maximum seasonal values as observed from the various time series. We use all the available data even if they consist of a few years. As a result in some stations there may not be data available for a particular season. However, the trends in the extremes are only estimated for the longest data sets (see Fig. 2).
We cannot assess whether sea level extremes occurred where gaps in the observations exist. However we can check whether the gaps in the observations coincided with extremes in the modelled sea level by comparing the trends in the extremes in the complete barotropic model time series for the period 1958-2000 and for the restricted periods excluding periods during which gaps exist in the observations. There was no statistically significant differences in the trends. Further we alsoestimated the trends in the barotropic model time series for the complete period of operation of each tide gauge and for periods where the gaps existing in the tide-gauge data where artificially created in the model time series. Again there were no statistically significant differences in the derived trends. This suggests that the derived trends in this analysis are not significantly effected by the presence of gaps in the records at least as far as the direct atmospheric forcing component is concerned. 


\section{Extreme sea levels}

The various tide gauges span over different periods of time (Fig. 2). Thus it is possible that a tide gauge is in operation over a more energetic period of time while other tide gauges may not be operating during the same period. Nevertheless we consider instructive in starting our discussion of extremes by simply plotting the maximum value observed for each tide gauge in each season.

There is significant variance in observational extremes with values in the Atlantic exceeding $250 \mathrm{~cm}$ while in the Mediterranean are around 50-60 cm (Fig. 3a and Table 1). The spatial distribution of the observed maxima has been documented by Marcos et al. (2009). As expected the tidally dominated areas, the Atlantic coasts of the Iberian peninsula and the northern Adriatic Sea have the largest observed sea level values during the four seasons.

\subsection{The Atlantic coasts}

At the Atlantic coasts the observed maxima occur mainly in winter or, for a couple of stations (Vigo and Cascais) in autumn (Fig. 3a). Spring maxima are the lowest in all stations. The maximum observed values reduce by almost a meter as we move from the Bay of Biscay to Portugal and the southern coasts of Spain. The spatial distribution is primarily caused by the tides. This is demonstrated by examining the tidal residuals.

The maxima in the tidal residuals (Fig. 3b) do not show the same spatial pattern as shown by the observed maxima. They are highest at stations Vigo (no. 89) and Villagarcia (no. 91). The values of the maxima in the tidal residuals are less than half those of the maxima in the observations. Winter or autumn maxima values are the highest, with the predominant extreme occurring in autumn in most stations. Spring maxima are in most stations the smallest (Fig. 3b).

The model sea level values describe the contribution of atmospheric pressure and wind. The maxima in these time series (Fig. 3c) are between $20-60 \mathrm{~cm}$. Winter maxima are the highest in most stations with autumn maxima values in general about $5 \mathrm{~cm}$ lower and summer maxima values being the lowest. However there are stations, for example Bilbao (11), Santander 2 (75) and Gijon (33) where no seasonal variation in the seasonal maxima can be identified.

The maxima in the atmospherically corrected values are generally lower than those of the maxima in the tidal residuals (Fig. 3d). The seasonal spread of the maxima is in most stations reduced by the removal of the direct atmospheric effects through the model. The range in the maxima is then only about $15-20 \mathrm{~cm}$, consistent with an annual steric cycle of half that amplitude which is known to be the case for the Mediterranean (Tsimplis and Woodworth, 1995; Tsimplis and Spencer, 1997; Marcos and Tsimplis, 2007).

\subsection{Western Mediterranean}

The maxima values for this region are shown in Fig. 4. The maxima are largest at the stations near the Strait of Gibraltar but reduce at stations further inside the western Mediterranean Sea (Fig. 4a). The range of the maxima is between $55 \mathrm{~cm}$ in autumn to $20-30 \mathrm{~cm}$ for the maxima of summer or spring values.

The removal of the tidal signal reduces the maximum values below $60 \mathrm{~cm}$ in all stations (Fig. 4b). The autumn maxima remain the highest indicating that the contribution of the steric seasonal cycle is important. The range between the seasonal extremes is less than $20 \mathrm{~cm}$ in most stations.

The maxima in the model values are highest in winter for almost all stations apart from Valencia (no. 85) (Fig. 4c). The maxima in the spring values, when the seasonal cycle of the model peaks (Marcos and Tsimplis, 2007) are the second largest maxima. The summer season has the lowest maxima, around $10-15 \mathrm{~cm}$ at most stations.

The maxima in the atmospherically corrected sea level values are up to $50 \mathrm{~cm}$ for the stations closest to the Strait of Gibraltar and reduce to $30 \mathrm{~cm}$ or less further in the western Mediterranean basin (Fig. 4d). Spring values are the lowest corresponding to the minimum of the steric cycle. The range of the seasonal maxima is now reduced to between 10 and $20 \mathrm{~cm}$.

\subsection{Eastern Mediterranean}

The spatial distribution of the maxima in the Eastern Mediterranean (Fig. 5) basin indicate two areas where the maxima are higher. The first is the Adriatic Sea where the maxima are higher than the rest of the eastern Mediterranean basin during all four seasons. The second area is the Aegean Sea where enhancement of the winter and autumn maxima is evident in the most northern stations but at a lesser extent than in the Adriatic Sea.

For the eastern Mediterranean five areas can be distinguished. First the stations between the Strait of Sicily and the Strait of Otrando where maxima of around $50 \mathrm{~cm}$ occur either in winter or autumn. These are by $10-20 \mathrm{~cm}$ higher than the maxima in spring or summer.

Second the area in the Adriatic where the maxima reach almost $200 \mathrm{~cm}$.

The third area is the Ionian Sea where the observed sea level maxima are less than $40 \mathrm{~cm}$. In this area the larger maxima occur in autumn or winter. The maxima for summer and spring are as small as $20 \mathrm{~cm}$.

The fourth area is the Aegean Sea the maxima reach values up to $60 \mathrm{~cm}$. North Halkis (no. 56) is a station with particularities (Tsimplis, 1997). The highest maxima in this fourth area as well as in the fifth area, consisting of stations in the southern Aegean and Eastern Mediterranean are predominantly found in the winter. 


\section{Western Mediterranean Basin}

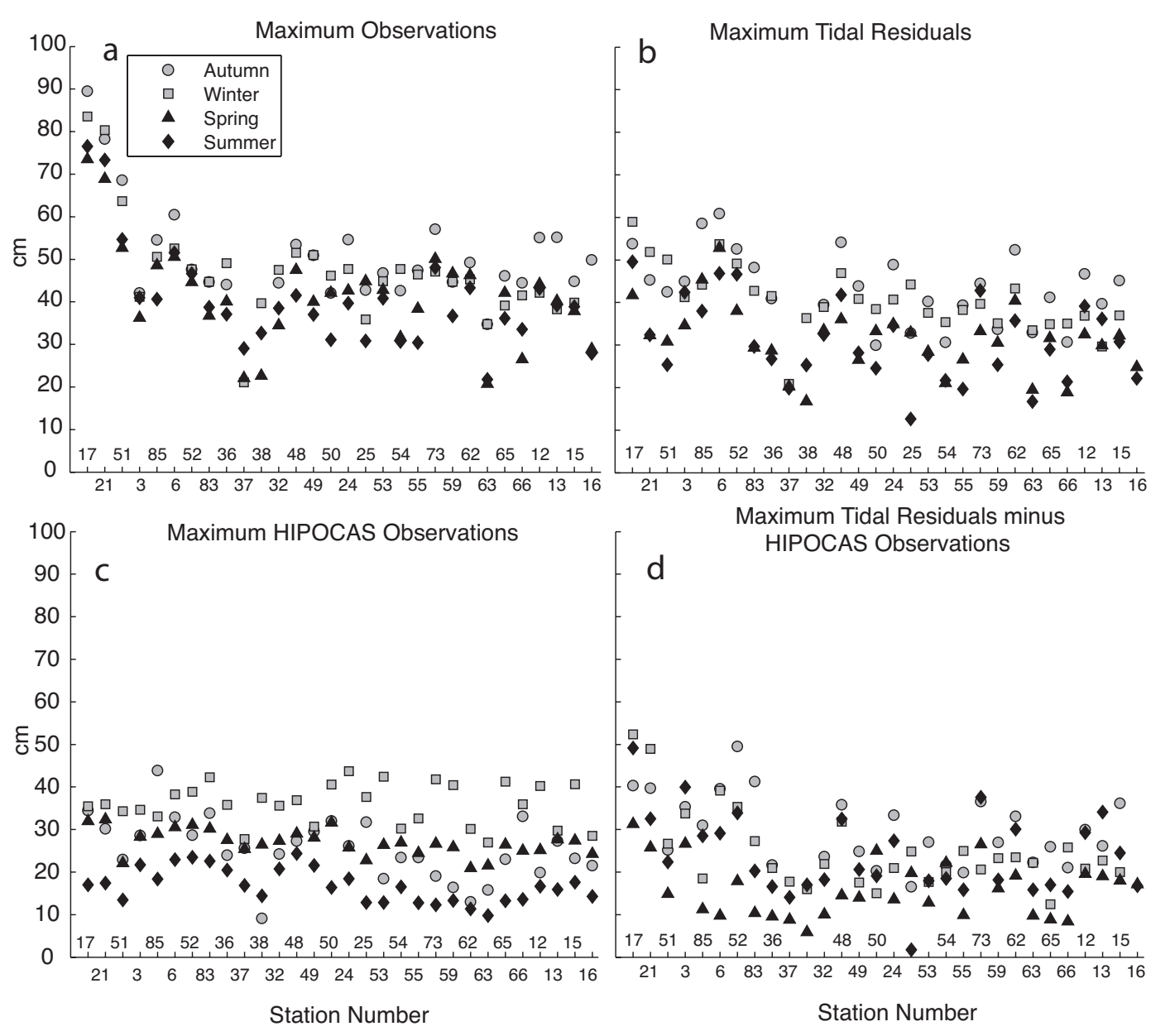

Fig. 4. As Fig. 3 for the western Mediterranean tide-gauges.

The removal of the tidal signal, which is generally small, apart from the Adriatic Sea and the station of North Halkis reduces the maxima in some of the stations The values of extremes in the Aegean Sea and the eastern Mediterranean appear now more spatially consistent (Fig. 5b). In the Adriatic Sea maxima values of up to $180 \mathrm{~cm}$ in autumn occur. The winter maxima are significantly smaller by around 40 $50 \mathrm{~cm}$. The spread between seasonal maxima in the other areas of the eastern Mediterranean is around $20 \mathrm{~cm}$.

The model maxima (Fig. 5c) occur in winter in all areas and reach up to $45 \mathrm{~cm}$ apart from the north Adriatic stations where the maxima occur in autumn and reach $150 \mathrm{~cm}$. The other seasons show values smaller by $10-20 \mathrm{~cm}$, the summer maxima being the lowest.

The maxima in the atmospherically corrected time series are smaller than the maxima in the tidal residuals in all areas (Fig. 5d). Maxima in the atmospherically corrected time series are around $30 \mathrm{~cm}$ for winter and autumn and less than $20 \mathrm{~cm}$, in some cases less than $10 \mathrm{~cm}$ in spring. Notably the pattern in the Adriatic Sea of the very high maxima found in the observations and in the tidal residuals still occurs in the atmospherically corrected maxima. This indicates that factors other than those described and modeled here contribute to the creation of maxima. It is possible that the discrepancy is due to the unsatisfactory resolution of local winds as suggested by Wakelin et al. (1999) and Wakelin and Proctor (2002) and to the basin resonance of the Adriatic Sea not correctly resolved by the model. However note that the barotropic model used here is forced by downscaled atmospheric parameters while those studied by Wakelin et al. (1999) and Wakelin and Proctor (2002) were not using downscaled atmospheric forcing.

\section{Trends in extreme sea levels}

Only the eleven stations with records longer than 34 years have been used in this part of the work (Fig. 2). The linear trends were calculated seasonally and the results are shown in Table 2. The statistically significant trends are shown in Fig. 6. 


\section{Eastern Mediterranean Basin}

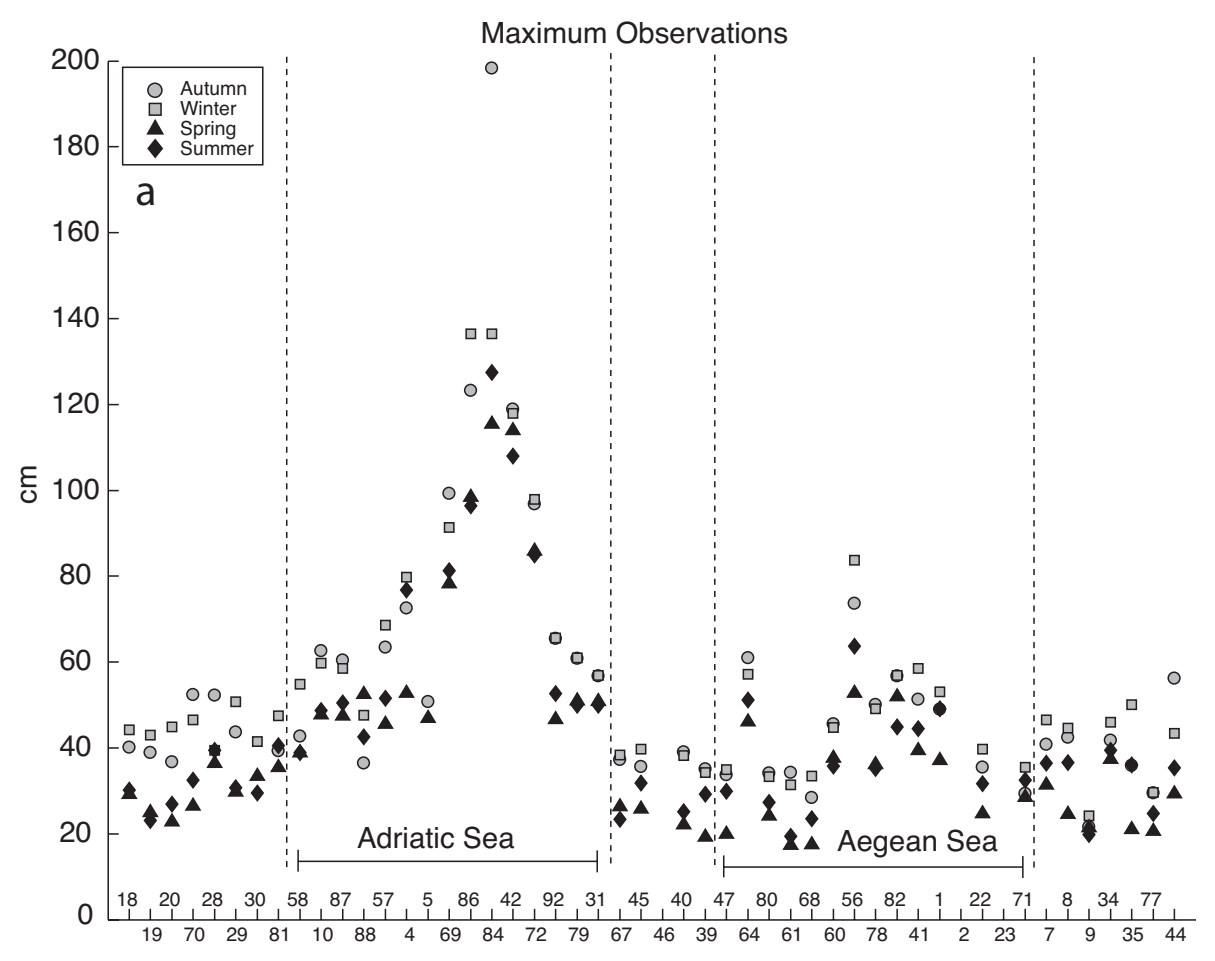

Eastern Mediterranean Basin

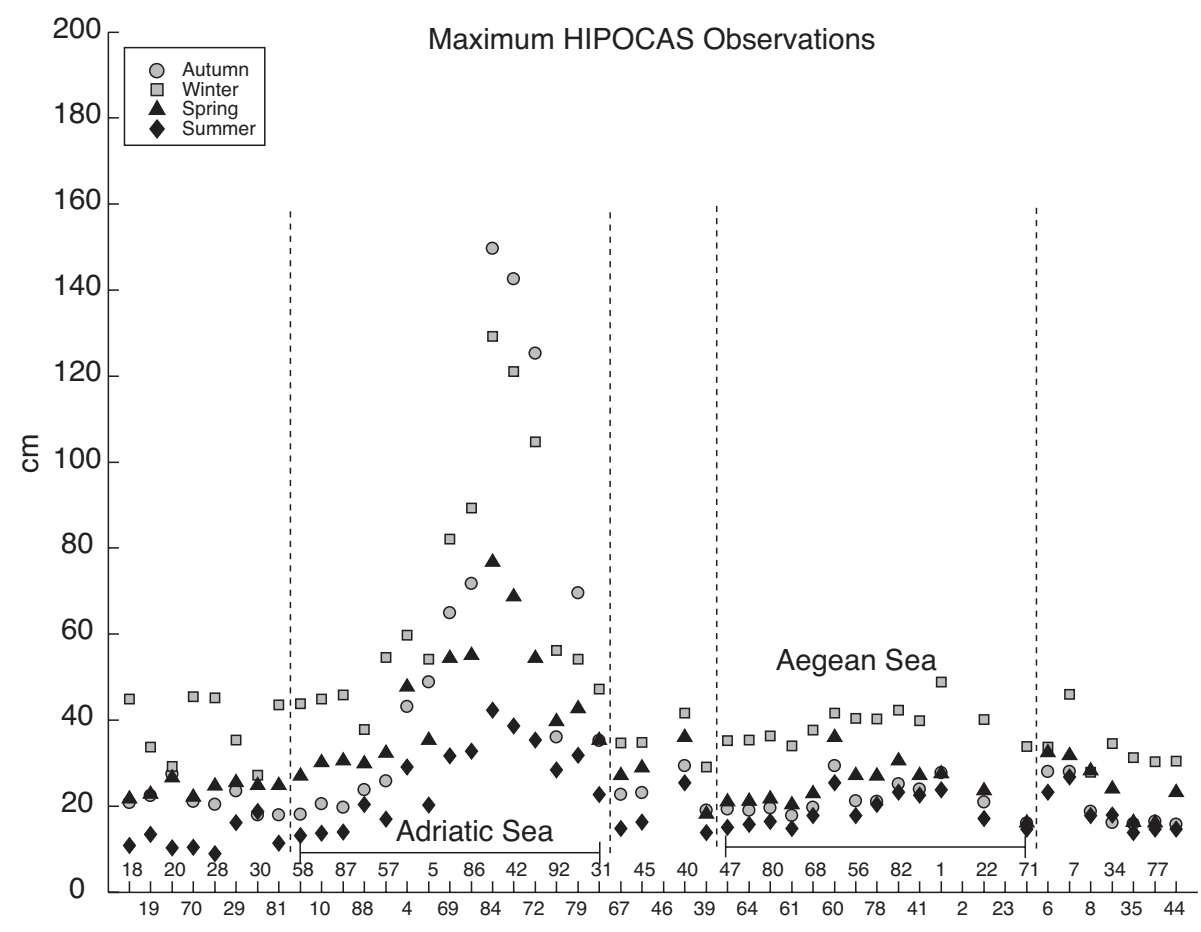

Fig. 5. As Fig. 3 for the eastern Mediterranean tide-gauges.

The trends in the $99.9 \%$ percentile of the observed values are mostly positive (Table 2). In the Atlantic coasts, the strongest positive trends are found for autumn and the small- est for winter. There is no consistency in the trends estimated for the stations in the western Mediterranean (Alicante and Ceuta) but the highest trend values are those of summer. In 

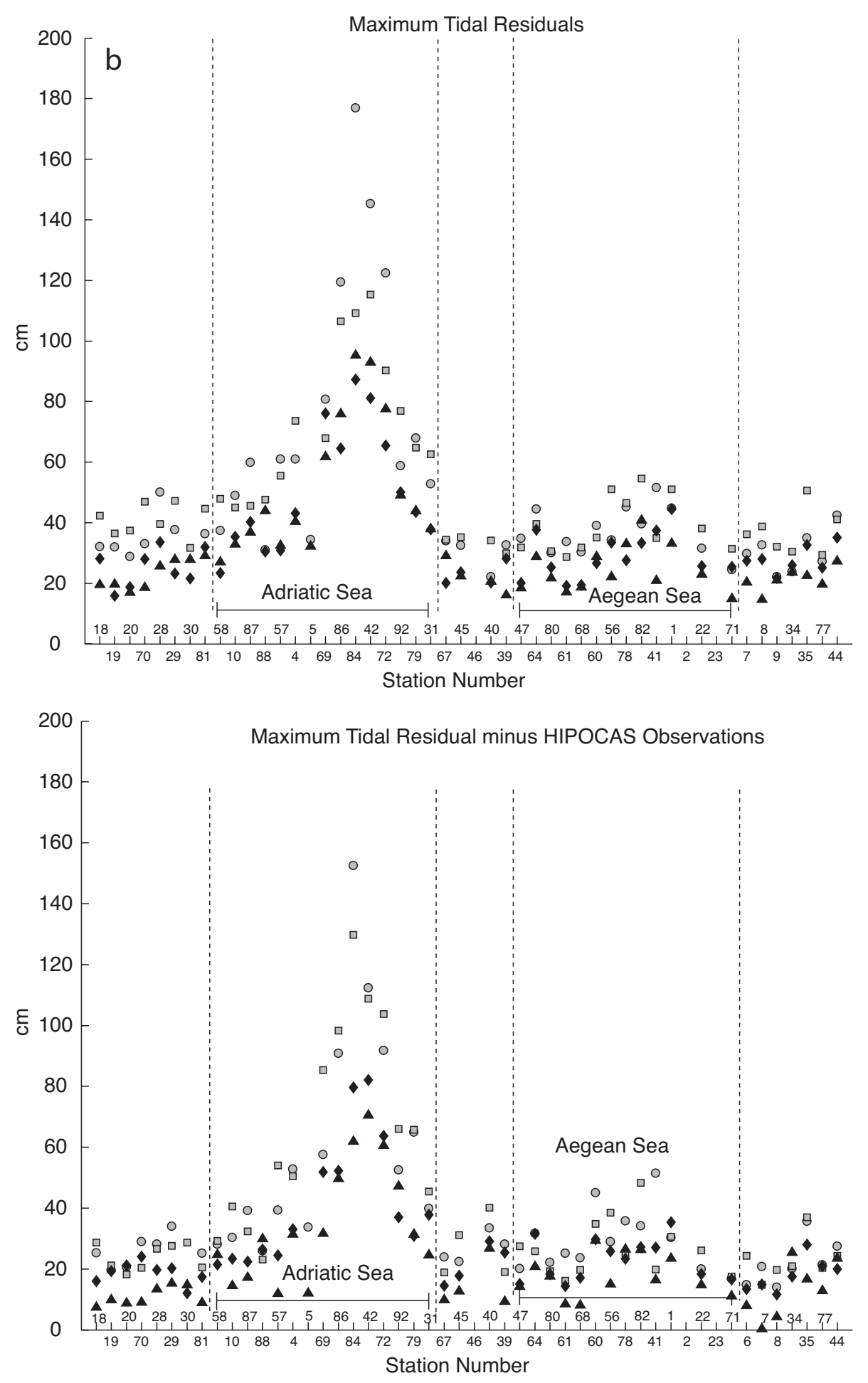

Fig. 5. Continued.

the Adriatic Sea the highest trends in the 99.9 percentile of the observed values are found in the spring, one of the periods where the occurring extreme values are low in comparison with other seasons.
The trends estimated on the $50 \%$ show a well known pattern in mean sea level (Tsimplis and Baker, 2000) consisting of trends in the Atlantic coasts higher than those within the Mediterranean Sea (Fig. 6b). The winter observations are those that have strong negative trends with the other seasons 

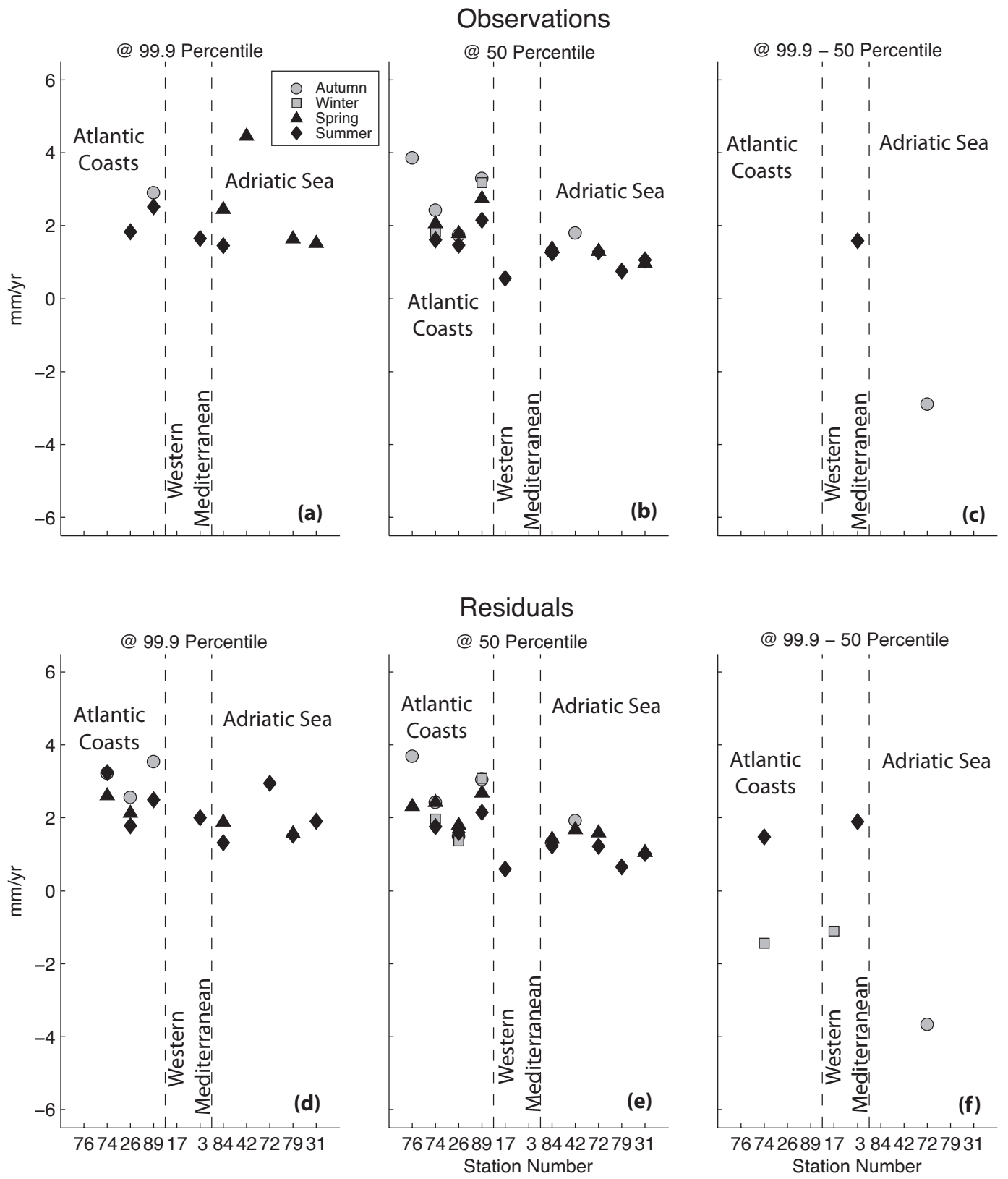

Fig. 6. Significant trends in the 99.9 and 50 percentiles and their differences. (a-c) for the observed values; (d-f) for the tidal residuals; (g-i) for the model values; $(\mathbf{j}-\mathbf{l})$ for the corrected by the model tidal residuals.

having small positive trends. When the observed trends of the $99.9 \%-50 \%$ are calculated (Table 2) most trends in all seasons fall within $\pm 0.5 \mathrm{~mm} / \mathrm{yr}$ with a (not statistically significant) tendency for the Atlantic stations to show small negative trends. This means that for the Atlantic the increases in the mean are slightly higher than the increases in the $99.9 \%$. The most remarkable changes occur at stations Koper (42) and Rovinj (72) where autumn values show significantly negative trends. Taking into account that for the Adriatic autumn shows maxima values, this is a positive, from the point of view of coastal protection, development. Notably in Koper
(42) it appears that the winter and spring extremes have been increasing in time.

The median values of the tidal residuals are of course very close to those of the observations (Fig. 6d, e, f). However, the $99.9 \%$ do show significant differences at the seasonal trends although the overall feature of predominantly positive trends in the Atlantic and a wider spread in the Mediterranean remains . The $99.9 \%-50 \%$ trends have a general pattern of highest trends in summer. A very high spread in the trends at Koper (42) and Rovinj (72) appears inconsistent with the spread of seasonal trends in the other stations. 


\section{HIPOCAS}
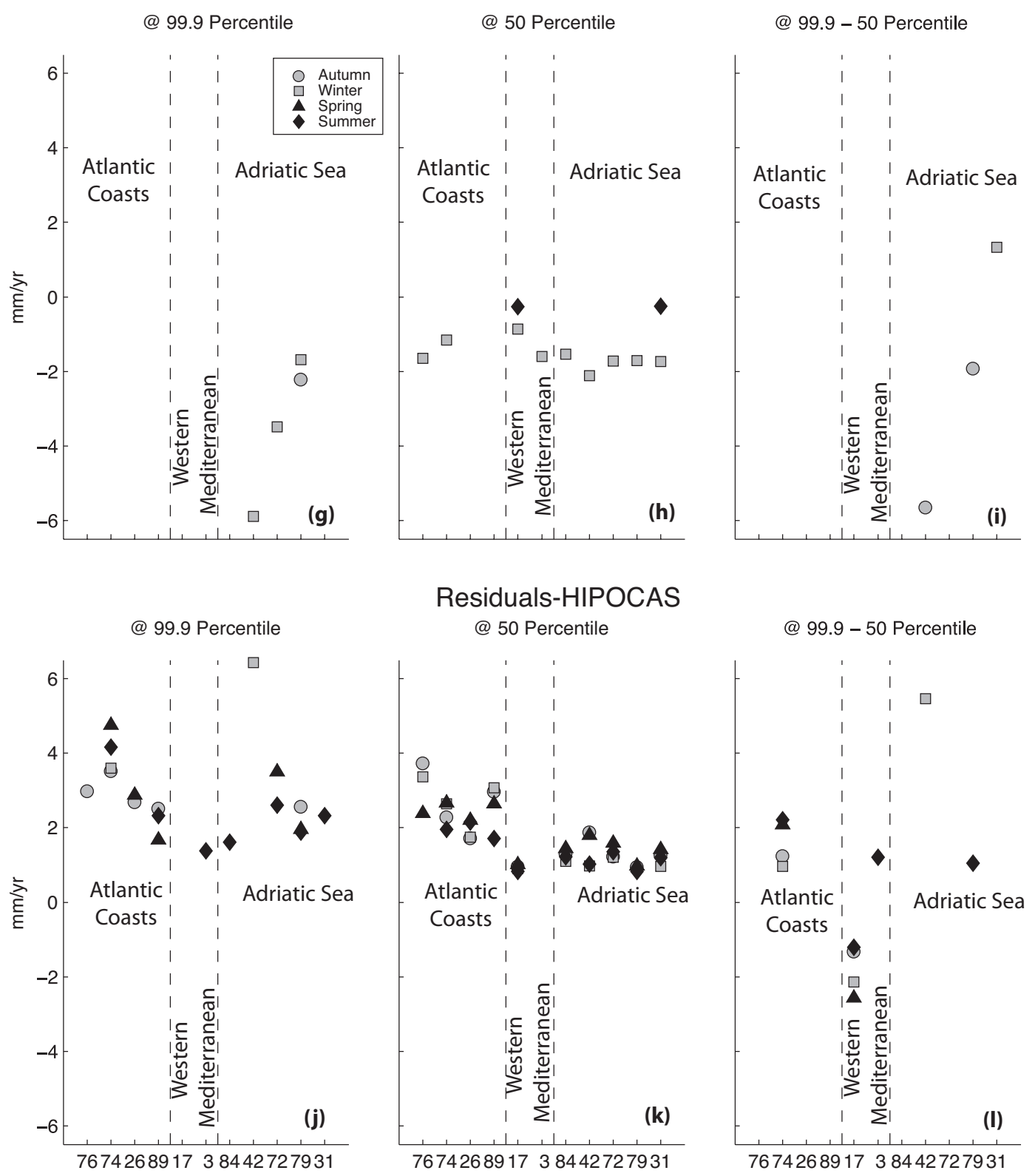

Fig. 6. Continued.

The modeled sea level data are less noisy than observations and as a consequence the estimated trends of the $99.9 \%$ and 50\% are more consistent (Fig. 6g, h, i). Starting from the $50 \%$ (Fig. 6h) negative mean sea level trends are found with very small positive trends in spring and no trends in the median values in the other seasons.

The $99.9 \%$ percentiles show in the Atlantic positive trends in summer and negative trends in winter in many stations and positive trends but in fewer stations in autumn (Fig. 6g). Small negative trends are found in the $99.9 \%$ for all seasons in the western Mediterranean Sea. The stations of the
Adriatic Sea show significant reductions $(4-6 \mathrm{~mm} / \mathrm{yr})$ in the 99.9\% in autumn and winter and almost no change in spring and summer.

The $99.9 \%-50 \%$ trends are significant in the Adriatic in winter and autumn. These are negative indicating reduction of wind and or increases of maxima of atmospheric pressure (Fig. 6i). Positive trends in summer are found in the Atlantic sector with negative trends in autumn and spring in some of the stations.

The atmospherically corrected time series have trends in the $99.9 \%$ with a larger spread than those of the observations. 
Table 2. Seasonal trends for the 99.9 percentile, the 50 percentile and the $99.9-50$ percentile in $\mathrm{mm} / \mathrm{yr}$. There are four columns for each season that correspond to the trend estimated from tide gauge observations, tidal residuals, the model values (HIPOCAS) and the tide residuals minus HIPOCAS, respectively. Note, that because HIPOCAS covers the period 1958 and 2001, the trend estimates at the fourth column of each season only covers the overlapping period between HIPOCAS data and the corresponding tide-gauge record. The error bars are those of the linear fit at the $95 \%$ level of significance.

\begin{tabular}{|c|c|c|c|c|c|c|c|c|c|c|c|}
\hline \multirow[b]{3}{*}{3} & \multirow{3}{*}{$\begin{array}{l}\text { Station name } \\
\text { Alicante }\end{array}$} & & & \multicolumn{4}{|c|}{ Autumn@ 99.9\% } & \multicolumn{4}{|c|}{ Winter@ 99.9\% } \\
\hline & & \multicolumn{2}{|c|}{ Period } & Obs & Tide_Res & Hip & Hip-Res & Obs & Tide-Res & Hip & Hip-Res \\
\hline & & 1957 & 1997 & $0.3 \pm 1.5$ & $0.0 \pm 1.7$ & $-0.7 \pm 1.4$ & $-0.3 \pm 1.4$ & $-0.6 \pm 1.9$ & $-0.9 \pm 2.0$ & $-1.3 \pm 1.4$ & $0.0 \pm 1.3$ \\
\hline 26 & Coruna & 1943 & 2000 & $1.6 \pm 2.3$ & $2.6 \pm 1.9$ & $0.0 \pm 2.4$ & $2.7 \pm 2.1$ & $0.4 \pm 2.1$ & $0.9 \pm 2.1$ & $-1.0 \pm 2.1$ & $1.6 \pm 2.0$ \\
\hline 31 & Dubrovnik & 1956 & 2001 & $0.4 \pm 1.5$ & $0.5 \pm 1.6$ & $-1.0 \pm 1.2$ & $1.1 \pm 1.5$ & $-0.6 \pm 1.6$ & $-0.1 \pm 2.1$ & $-0.4 \pm 1.4$ & $0.6 \pm 1.7$ \\
\hline 42 & Koper & 1962 & 1999 & $-1.0 \pm 4.0$ & $-1.2 \pm 6.6$ & $-5.7 \pm 5.9$ & $0.9 \pm 5.2$ & $1.8 \pm 3.3$ & $3.0 \pm 4.2$ & $-5.9 \pm 4.0$ & $6.4 \pm 5.2$ \\
\hline 76 & Sjluz & 1964 & 2003 & $2.5 \pm 6.4$ & $2.2 \pm 4.4$ & $-1.2 \pm 2.7$ & $3.0 \pm 2.5$ & $1.3 \pm 4.3$ & $0.1 \pm 3.9$ & $-1.4 \pm 2.5$ & $1.8 \pm 3.3$ \\
\hline 79 & Split & 1956 & 2001 & $-0.3 \pm 1.7$ & $0.2 \pm 2.3$ & $-2.2 \pm 2.0$ & $2.6 \pm 2.1$ & $-0.1 \pm 1.6$ & $-0.5 \pm 2.3$ & $-1.7 \pm 1.5$ & $0.9 \pm 2.1$ \\
\hline 84 & Trieste & 1939 & 2005 & $0.6 \pm 2.7$ & $2.1 \pm 3.6$ & $-4.4 \pm 4.8$ & $-2.3 \pm 5.2$ & $1.4 \pm 1.8$ & $1.5 \pm 2.0$ & $-3.5 \pm 3.9$ & $1.5 \pm 4.2$ \\
\hline \multirow[t]{3}{*}{89} & Vigo & 1943 & 2000 & $2.9 \pm 2.4$ & $3.6 \pm 2.1$ & $0.1 \pm 2.3$ & $2.5 \pm 2.2$ & $1.7 \pm 2.0$ & $2.2 \pm 2.2$ & $-1.1 \pm 2.1$ & $2.0 \pm 2.1$ \\
\hline & & & & \multicolumn{4}{|c|}{ Autumn@ 05} & \multicolumn{4}{|c|}{ Winter@ 50\% } \\
\hline & Station name & \multicolumn{2}{|c|}{ Period } & Obs & Tide_Res & Hip & Res-Hip & Obs & Tide-Res & Hip & Res-Hip \\
\hline 3 & Alicante & 1957 & 1997 & $-0.5 \pm 1.0$ & $-0.5 \pm 1.1$ & $-0.4 \pm 0.8$ & $0.5 \pm 0.6$ & $-1.1 \pm 1.5$ & $-1.1 \pm 1.5$ & $-1.6 \pm 0.9$ & $0.3 \pm 0.7$ \\
\hline 17 & Ceuta & 1944 & 2002 & $0.5 \pm 0.7$ & $0.5 \pm 0.7$ & $-0.5 \pm 0.5$ & $\mathbf{1 . 0} \pm \mathbf{0 . 8}$ & $0.1 \pm 0.6$ & $0.1 \pm 0.6$ & $-0.9 \pm 0.6$ & $0.9 \pm 0.7$ \\
\hline 26 & Coruna & 1943 & 2000 & $1.8 \pm 1.1$ & $1.5 \pm 1.1$ & $-0.1 \pm 1.0$ & $1.7 \pm 1.1$ & $1.2 \pm 1.2$ & $1.4 \pm 1.3$ & $-1.0 \pm 1.2$ & $1.7 \pm 1.2$ \\
\hline 31 & Dubrovnik & 1956 & 2001 & $0.8 \pm 1.3$ & $0.8 \pm 1.4$ & $-0.2 \pm 0.8$ & $1.3 \pm 0.8$ & $-0.6 \pm 1.3$ & $-0.6 \pm 1.3$ & $-1.7 \pm 1.0$ & $\mathbf{1 . 0} \pm \mathbf{0 . 7}$ \\
\hline 42 & Koper & 1962 & 1999 & $1.8 \pm 1.8$ & $1.9 \pm 1.8$ & $-0.1 \pm 1.2$ & $1.9 \pm 0.9$ & $-0.9 \pm 1.7$ & $-1.2 \pm 1.8$ & $-2.1 \pm 1.3$ & $\mathbf{1 . 0} \pm \mathbf{0 . 9}$ \\
\hline 72 & Rovinj & 1959 & 2001 & $0.9 \pm 1.4$ & $0.9 \pm 1.5$ & $-0.3 \pm 1.0$ & $1.2 \pm 0.7$ & $-0.5 \pm 1.7$ & $-0.7 \pm 1.7$ & $-1.7 \pm 1.1$ & $1.2 \pm 0.9$ \\
\hline 74 & Santander & 1943 & 2000 & $2.4 \pm 1.0$ & $2.4 \pm 1.1$ & $-0.2 \pm 1.0$ & $2.3 \pm 1.2$ & $1.8 \pm 1.1$ & $2.0 \pm 1.2$ & $-1.2 \pm 1.1$ & $2.6 \pm 1.0$ \\
\hline 76 & Sjluz & 1964 & 2003 & $3.9 \pm 2.7$ & $3.7 \pm 2.8$ & $0.1 \pm 1.2$ & $3.7 \pm 1.8$ & $1.4 \pm 2.1$ & $1.8 \pm 2.2$ & $-1.7 \pm 1.6$ & $3.4 \pm 1.5$ \\
\hline 79 & Split & 1956 & 2001 & $0.6 \pm 1.4$ & $0.6 \pm 1.5$ & $-0.3 \pm 0.9$ & $0.9 \pm 0.8$ & $-0.9 \pm 1.4$ & $-0.9 \pm 1.4$ & $-1.7 \pm 1.0$ & $0.4 \pm 0.8$ \\
\hline 84 & Trieste & 1939 & 2005 & $1.3 \pm 0.8$ & $1.3 \pm \mathbf{0 . 8}$ & $-0.3 \pm 1.0$ & $1.3 \pm 0.8$ & $0.7 \pm 0.8$ & $0.6 \pm 0.8$ & $-1.5 \pm 1.1$ & $\mathbf{1 . 1} \pm \mathbf{0 . 7}$ \\
\hline \multirow[t]{3}{*}{89} & Vigo & 1943 & 2000 & $3.3 \pm 1.1$ & $3.1 \pm 1.1$ & $-0.1 \pm 1.0$ & $3.0 \pm 1.3$ & $3.2 \pm 1.2$ & $3.1 \pm 1.2$ & $-1.1 \pm 1.1$ & $3.1 \pm 1.3$ \\
\hline & & \multirow{2}{*}{\multicolumn{2}{|c|}{ Period }} & \multicolumn{4}{|c|}{ Autumn@99.9\%-50\% } & \multicolumn{4}{|c|}{ Winter@99.9\%-50\% } \\
\hline & Station name & & & Obs & Tide_Res & Hip & Hip-Res & Obs & Tide-Res & Hip & Hip-Res \\
\hline 3 & Alicante & 1957 & 1997 & $0.8 \pm 1.5$ & $0.5 \pm 1.7$ & $-0.3 \pm 1.2$ & $-0.8 \pm 1.3$ & $0.5 \pm 1.5$ & $0.2 \pm 1.5$ & $0.3 \pm 1.3$ & $-0.3 \pm 1.1$ \\
\hline 17 & Ceuta & 1944 & 2002 & $-0.6 \pm 1.0$ & $0.1 \pm 1.0$ & $-0.2 \pm 1.5$ & $-1.3 \pm 1.2$ & $-0.1 \pm 0.7$ & $-1.1 \pm 1.1$ & $-0.2 \pm 1.3$ & $-2.1 \pm 1.9$ \\
\hline 26 & Coruna & 1943 & 2000 & $-0.1 \pm 1.9$ & $1.1 \pm 1.5$ & $0.1 \pm 2.2$ & $1.0 \pm 1.8$ & $-0.8 \pm 1.6$ & $-0.4 \pm 1.6$ & $0.1 \pm 2.0$ & $-0.2 \pm 1.6$ \\
\hline 31 & Dubrovnik & 1956 & 2001 & $-0.4 \pm 1.5$ & $-0.4 \pm 1.6$ & $-0.8 \pm 1.3$ & $-0.2 \pm 1.2$ & $-0.0 \pm 1.3$ & $0.5 \pm 1.7$ & $1.3 \pm 1.3$ & $-0.3 \pm 1.3$ \\
\hline 42 & Koper & 1962 & 1999 & $-2.8 \pm 3.6$ & $-3.1 \pm 5.6$ & $-5.7 \pm 5.4$ & $-0.9 \pm 4.8$ & $2.7 \pm 3.0$ & $4.2 \pm 4.3$ & $-3.8 \pm 4.1$ & $5.5 \pm 5.2$ \\
\hline 72 & Rovinj & 1959 & 2001 & $-2.9 \pm 2.6$ & $-3.7 \pm 3.6$ & $-3.6 \pm 3.8$ & $-1.3 \pm 3.3$ & $0.2 \pm 2.0$ & $1.4 \pm 3.1$ & $-1.8 \pm 3.1$ & $2.7 \pm 3.9$ \\
\hline 74 & Santander & 1943 & 2000 & $0.5 \pm 2.8$ & $0.8 \pm 1.2$ & $-0.7 \pm 1.5$ & $1.2 \pm 1.2$ & $-1.1 \pm 1.6$ & $-1.4 \pm 1.4$ & $0.1 \pm 1.7$ & $\mathbf{1 . 0} \pm \mathbf{1 . 0}$ \\
\hline 76 & Sjluz & 1964 & 2003 & $-1.4 \pm 5.4$ & $-1.5 \pm 3.1$ & $-1.3 \pm 2.2$ & $-0.7 \pm 1.6$ & $-0.0 \pm 3.6$ & $-1.7 \pm 3.5$ & $0.2 \pm 2.9$ & $-1.6 \pm 2.9$ \\
\hline 79 & Split & 1956 & 2001 & $-0.8 \pm 1.4$ & $-0.4 \pm 1.8$ & $-1.9 \pm 1.9$ & $1.6 \pm 1.8$ & $0.8 \pm 1.3$ & $0.4 \pm 1.9$ & $0.0 \pm 1.5$ & $0.5 \pm 2.0$ \\
\hline 84 & Trieste & 1939 & 2005 & $-0.7 \pm 2.5$ & $0.7 \pm 3.3$ & $-4.1 \pm 4.4$ & $-3.6 \pm 5.0$ & $0.8 \pm 1.5$ & $1.0 \pm 1.8$ & $-1.9 \pm 3.9$ & $0.4 \pm 4.2$ \\
\hline 89 & Vigo & 1943 & 2000 & $-0.4 \pm 1.9$ & $0.5 \pm 1.6$ & $0.3 \pm 2.2$ & $-0.5 \pm 1.6$ & $-1.5 \pm 1.6$ & $-0.9 \pm 1.7$ & $-0.1 \pm 1.9$ & $-1.1 \pm 1.8$ \\
\hline
\end{tabular}

In addition although the spread of seasonal trends is reduced in relation to that of the trends in the $99.9 \%$ of the observations the difference in the trends between stations appear increased (Fig. 6j).

By contrast the $50 \%$ of the atmospherically corrected trends are much more spatially consistent than the trends in the $50 \%$ of either the observations or the tidal residuals. Positive trends of around $3 \mathrm{~mm} / \mathrm{yr}$ in the Atlantic and about
$1.7 \mathrm{~mm} / \mathrm{yr}$ in the Adriatic Sea and with very little difference seasonally (Fig. 6k) are found. Smaller values, less than $1 \mathrm{~mm} / \mathrm{yr}$, are found in the western Mediterranean.

The atmospheric correction reduces the spread in the trends between seasons of the $50 \%$ values. However it does not have the same effect on the trends of the 99.9 percentile. As a result spatial patterns in these trends or the trends of the 99.9-50 percentile cannot be identified as the spread of 
Table 2. Continued.

\begin{tabular}{|c|c|c|c|c|c|c|c|c|c|c|c|}
\hline \multirow[b]{3}{*}{3} & \multirow{3}{*}{$\begin{array}{l}\text { Station name } \\
\text { Alicante }\end{array}$} & & & \multicolumn{4}{|c|}{ Spring@ @99.9\% } & \multicolumn{4}{|c|}{ Summer@99.9\% } \\
\hline & & \multicolumn{2}{|c|}{ Period } & Obs & Tide_Res & Hip & Res-Hip & Obs & Tide-Res & Hip & Res-Hip \\
\hline & & 1957 & 1997 & $-0.1 \pm 1.6$ & $-0.6 \pm 1.7$ & $-0.3 \pm 1.1$ & $1.1 \pm 1.6$ & $1.6 \pm 1.4$ & $2.0 \pm 1.4$ & $-0.3 \pm 0.7$ & $1.4 \pm 1.3$ \\
\hline 26 & Coruna & 1943 & 2000 & $1.0 \pm 2.5$ & $2.1 \pm 1.5$ & $-0.5 \pm 1.7$ & $2.9 \pm 1.4$ & $1.8 \pm 1.7$ & $1.8 \pm 1.2$ & $0.7 \pm 1.5$ & $1.1 \pm 1.8$ \\
\hline 31 & Dubrovnik & 1956 & 2001 & $1.5 \pm 1.4$ & $0.9 \pm 1.4$ & $0.1 \pm 1.2$ & $0.9 \pm 1.2$ & $0.9 \pm 1.2$ & $1.9 \pm 1.2$ & $-0.6 \pm 0.8$ & $2.3 \pm 1.3$ \\
\hline 42 & Koper & 1962 & 1999 & $4.5 \pm 3.9$ & $0.9 \pm 4.4$ & $0.4 \pm 2.7$ & $-0.2 \pm 3.8$ & $1.0 \pm 2.2$ & $2.0 \pm 3.2$ & $0.5 \pm 1.4$ & $1.1 \pm 3.0$ \\
\hline 76 & Sjluz & 1964 & 2003 & $-0.6 \pm 6.1$ & $2.0 \pm 4.0$ & $1.5 \pm 1.9$ & $1.4 \pm 3.2$ & $0.5 \pm 4.5$ & $-0.0 \pm 2.7$ & $1.6 \pm 1.9$ & $0.3 \pm 2.2$ \\
\hline 79 & Split & 1956 & 2001 & $1.6 \pm 1.5$ & $1.6 \pm 1.5$ & $-0.0 \pm 1.6$ & $2.0 \pm 1.3$ & $0.6 \pm 1.2$ & $1.5 \pm 1.3$ & $-0.6 \pm 1.0$ & $1.9 \pm 1.0$ \\
\hline 84 & Trieste & 1939 & 2005 & $2.5 \pm 1.6$ & $1.9 \pm 1.7$ & $0.3 \pm 2.3$ & $0.8 \pm 2.3$ & $1.5 \pm 1.1$ & $1.3 \pm 1.2$ & $0.2 \pm 1.2$ & $1.6 \pm 1.5$ \\
\hline \multirow[t]{2}{*}{89} & Vigo & 1943 & 2000 & $1.4 \pm 2.3$ & $1.5 \pm 1.8$ & $-0.6 \pm 1.7$ & $1.7 \pm 1.4$ & $2.5 \pm 1.8$ & $2.5 \pm 1.4$ & $0.5 \pm 1.4$ & $2.3 \pm 1.5$ \\
\hline & & \multicolumn{2}{|c|}{ Period } & \multicolumn{4}{|c|}{ Spring @ 50\% } & \multicolumn{4}{|c|}{ Summer@ $@ 50 \%$} \\
\hline 31 & Dubrovnik & 1956 & 2001 & $1.0 \pm \mathbf{0 . 9}$ & $\mathbf{1 . 0} \pm \mathbf{0 . 9}$ & $-0.5 \pm 0.5$ & $1.4 \pm 0.8$ & $1.1 \pm 0.6$ & $\mathbf{1 . 0} \pm \mathbf{0 . 6}$ & $-0.2 \pm 0.2$ & $1.2 \pm 0.6$ \\
\hline 42 & Koper & 1962 & 1999 & $1.4 \pm 1.4$ & $1.7 \pm 1.4$ & $-0.1 \pm 0.8$ & $1.8 \pm 1.0$ & $0.9 \pm 0.9$ & $0.7 \pm 0.8$ & $-0.2 \pm 0.3$ & $\mathbf{1 . 0} \pm \mathbf{0 . 8}$ \\
\hline 72 & Rovinj & 1959 & 2001 & $1.3 \pm 1.0$ & $1.6 \pm 1.1$ & $-0.2 \pm 0.6$ & $1.6 \pm 0.8$ & $\mathbf{1 . 3} \pm \mathbf{0 . 8}$ & $1.2 \pm 0.8$ & $-0.1 \pm 0.3$ & $1.4 \pm 0.8$ \\
\hline 74 & Santander & 1943 & 2000 & $2.1 \pm 1.0$ & $2.4 \pm 0.9$ & $0.5 \pm 0.7$ & $2.7 \pm 1.0$ & $1.6 \pm 0.6$ & $1.8 \pm 0.6$ & $-0.0 \pm 0.3$ & $2.0 \pm 0.8$ \\
\hline 76 & Sjluz & 1964 & 2003 & $2.1 \pm 2.4$ & $2.3 \pm 2.3$ & $-0.1 \pm 1.0$ & $2.4 \pm 1.8$ & $1.2 \pm 1.4$ & $1.1 \pm 1.4$ & $0.0 \pm 0.4$ & $1.2 \pm 1.4$ \\
\hline 79 & Split & 1956 & 2001 & $0.7 \pm 0.9$ & $0.7 \pm 0.9$ & $-0.2 \pm 0.5$ & $\mathbf{1 . 0} \pm \mathbf{0 . 7}$ & $0.7 \pm 0.5$ & $0.7 \pm 0.5$ & $-0.2 \pm 0.2$ & $\mathbf{0 . 8} \pm \mathbf{0 . 5}$ \\
\hline 84 & Trieste & 1939 & 2005 & $1.4 \pm 0.6$ & $1.4 \pm 0.5$ & $-0.2 \pm 0.6$ & $1.4 \pm 0.7$ & $1.2 \pm 0.3$ & $1.2 \pm 0.3$ & $-0.1 \pm 0.2$ & $1.2 \pm 0.5$ \\
\hline \multirow[t]{3}{*}{89} & Vigo & 1943 & 2000 & $2.7 \pm 0.9$ & $2.7 \pm 0.9$ & $0.7 \pm 0.8$ & $2.6 \pm 1.1$ & $2.2 \pm 0.7$ & $2.1 \pm 0.7$ & $0.1 \pm 0.2$ & $1.7 \pm 1.1$ \\
\hline & & \multirow{2}{*}{\multicolumn{2}{|c|}{ Period }} & \multicolumn{4}{|c|}{ Spring@ @9.9\%-50\% } & \multicolumn{4}{|c|}{ Summer@99.9\%-50\% } \\
\hline & Station name & & & Obs & Tide_Res & Hip & Res-Hip & Obs & Tide-Res & Hip & Res-Hip \\
\hline 79 & Split & 1956 & 2001 & $0.9 \pm 1.4$ & $0.9 \pm 1.3$ & $0.2 \pm 1.6$ & $1.0 \pm 1.2$ & $-0.2 \pm 1.0$ & $0.9 \pm 1.2$ & $-0.4 \pm 1.1$ & $1.1 \pm 0.9$ \\
\hline 84 & Trieste & 1939 & 2005 & $1.1 \pm 1.5$ & $0.5 \pm 1.6$ & $0.5 \pm 2.5$ & $-0.6 \pm 2.2$ & $0.2 \pm 1.0$ & $0.1 \pm 1.1$ & $0.3 \pm 1.2$ & $0.4 \pm 1.4$ \\
\hline 89 & Vigo & 1943 & 2000 & $-1.3 \pm 2.3$ & $-1.2 \pm 1.8$ & $-1.4 \pm 1.6$ & $-1.0 \pm 1.5$ & $0.4 \pm 1.6$ & $0.4 \pm 1.1$ & $0.4 \pm 1.4$ & $0.6 \pm 1.1$ \\
\hline
\end{tabular}

the values become too large. The reason why the trends in the $99.9 \%$ of the atmospherically corrected time series become spatially inconsistent is unknown. We speculate that the model has spatially variable skill in estimating extremes and this results into the diversity of the trends.

To assess the effect of the existing gaps in the tide-gauge records on the estimation of trends we have redone the analysis of extremes in the model data for the whole period covered by each tide-gauge but including all values for that period. We compared these results with the earlier described results where the trends were estimated for only the periods coinciding with those in which the tide-gauges had data and we found no significant differences in the derived trends.

\section{Correlation with atmospheric patterns}

It is well established that interannual variability within the Mediterranean Sea especially in the winter is significantly correlated with the North Atlantic Oscillation (see for example Tsimplis and Josey, 2001; Gomis et al., 2006). In addition significant sea level change over several decades have been driven by changes in the NAO (Tsimplis and Josey, 2001).

Marcos et al. (2009) have showed that extremes in the region correlate at some of the stations with the winter NAO and that this correlation disappears when the median value is removed. 

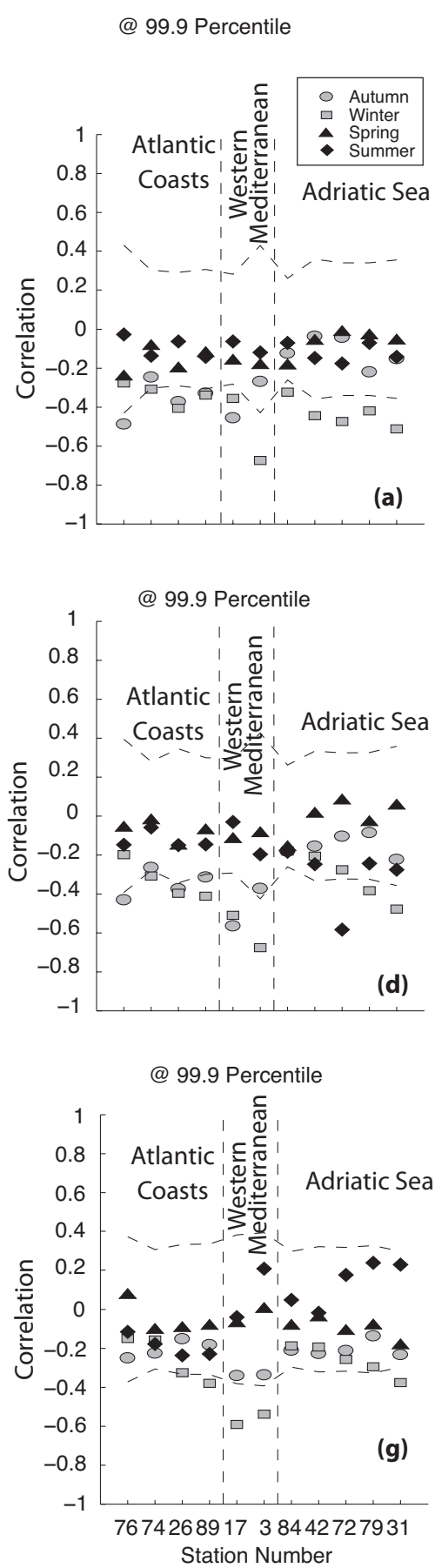

\section{Observations}

@ 50 Percentile

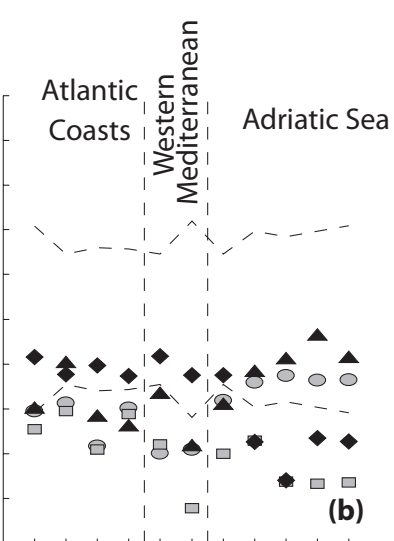

Tidal Residuals

@ 50 Percentile

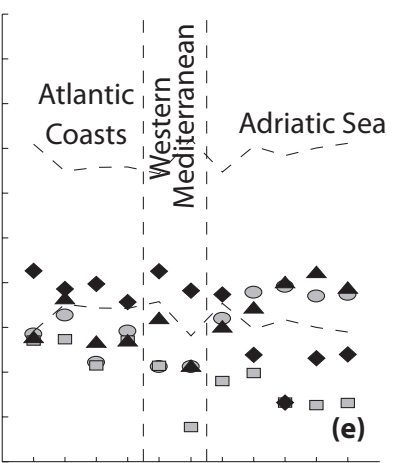

HIPOCAS

@ 50 Percentile

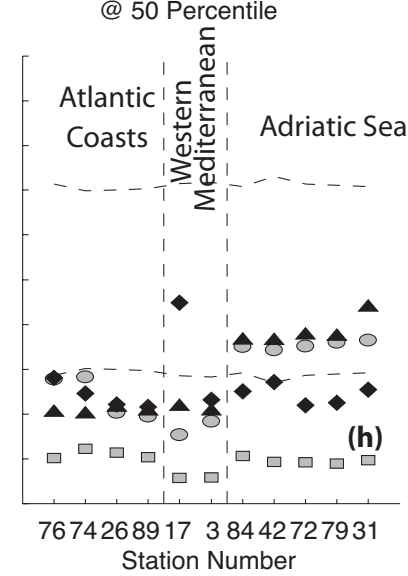

@ 99.9 - 50 Percentile
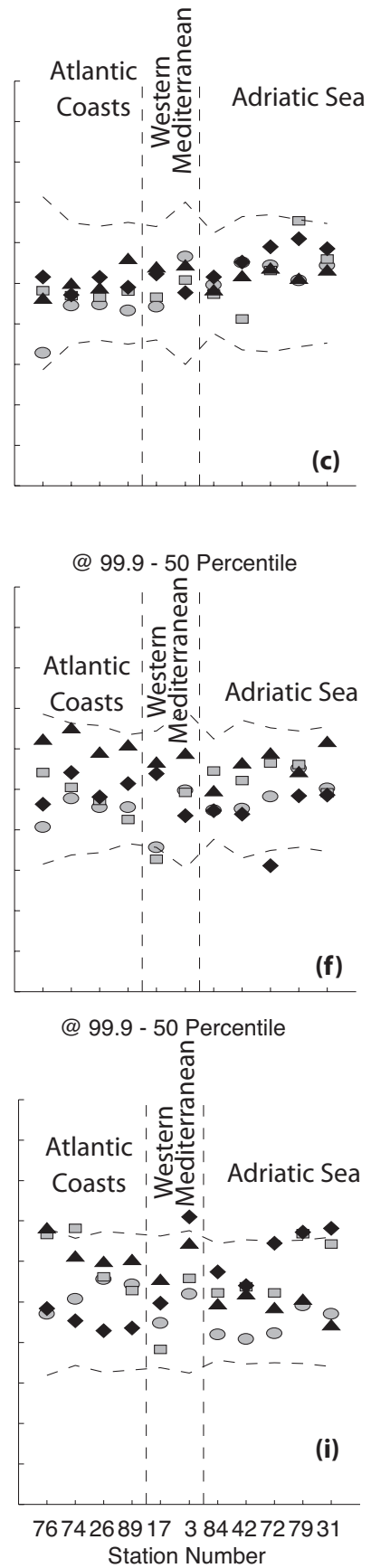

Fig. 7. Seasonal correlations of the NAO index with the 99.9 percentile, 50 percentile and their difference. (a-c) for the observed values; (d-f) for the tidal residuals; (g-i) for the model values. Each of the seasonal correlation coefficients has an associated value in order to be significant at $95 \%$ level. We have plotted the highest of the four values as giving the most conservative estimate for the level of significance.

Figure 7 shows the correlation coefficients for seasonal NAO values with the corresponding seasonal sea level percentiles. For the sea level observations the negative correlations are higher for winter both at $99.9 \%$ and at $50 \%$. In addition significant negative correlations are found for au- tumn in the Atlantic. Significant correlations are also found at the $50 \%$ percentile for most stations in the Adriatic during the summer season. Also significant correlations are found between the NAO and most Atlantic coast and Western Mediterranean stations during spring. The correlation 

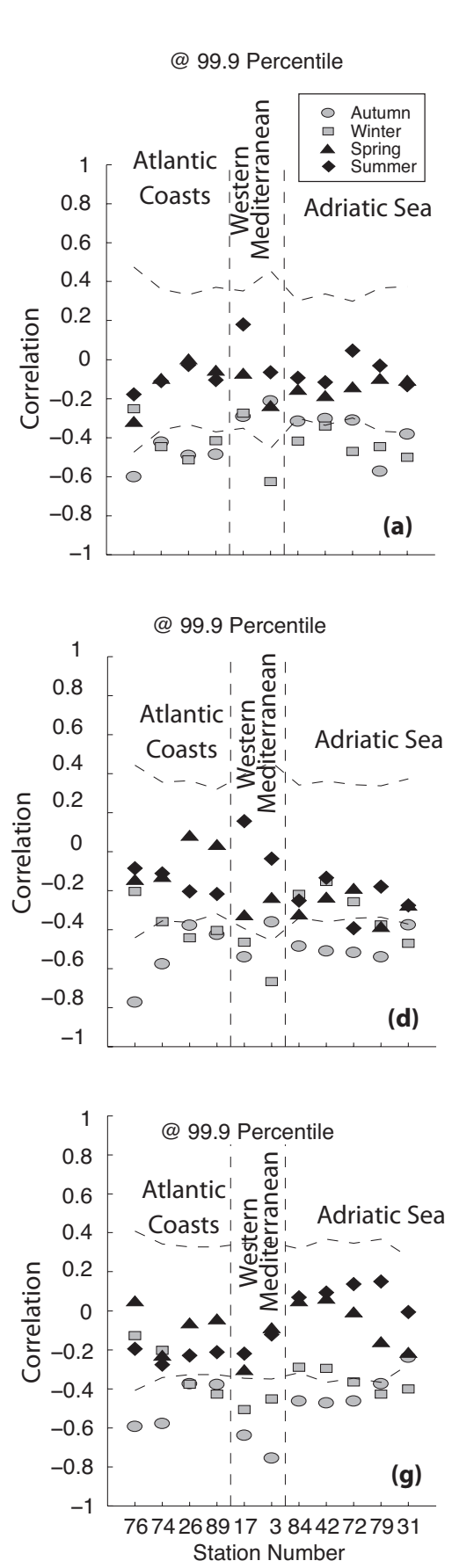

\section{Observations}

@ 50 Percentile

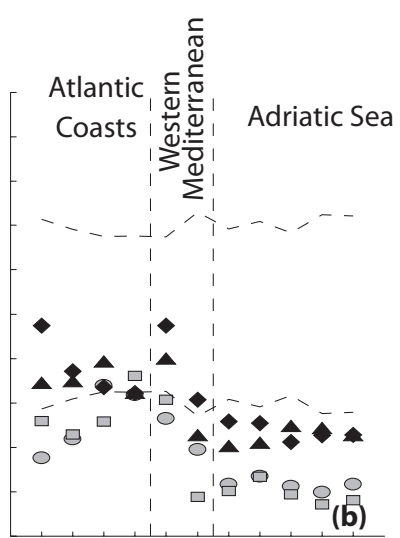

Tidal Residuals

@ 50 Percentile

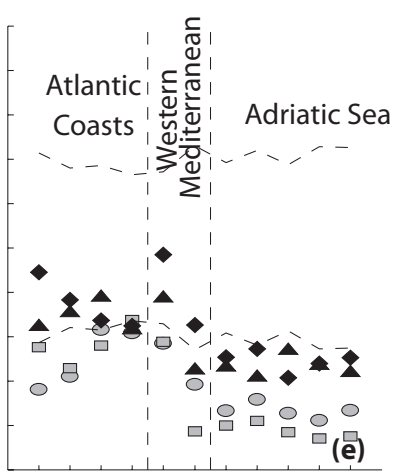

\section{HIPOCAS}

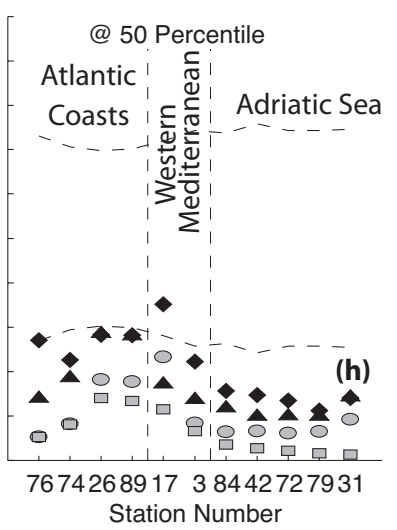

@ 99.9 - 50 Percentile

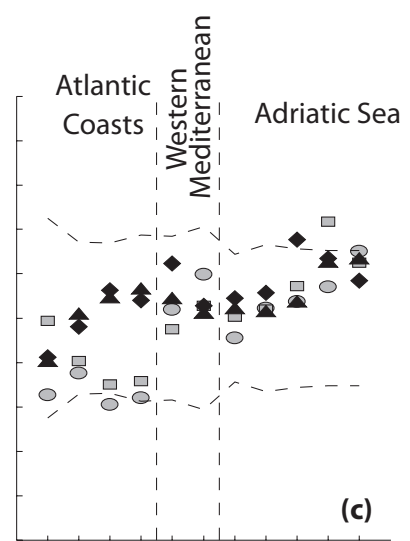

@ 99.9 - 50 Percentile

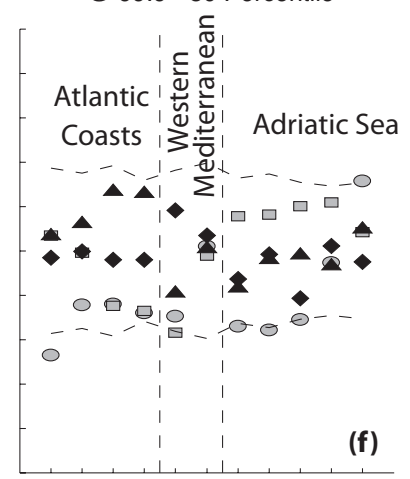

@ 99.9 - 50 Percentile

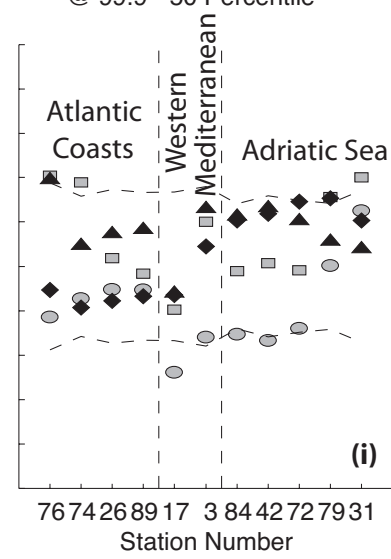

Fig. 8. Seasonal correlations of the MOI index with the 99.9 percentile, 50 percentile and their difference. (a-c) for the observed values; (d-f) for the tidal residuals; (g-i) for the model values. Each of the seasonal correlation coefficients has an associated value in order to be significant at $95 \%$ level. We have plotted the highest of the four values as giving the most conservative estimate for the level of significance.

between the NAO and the $99.9 \%$ percentile becomes statistically insignificant when the 50\% is subtracted (Fig. 7c). Thus the influence of the NAO at the $99.9 \%$ is due to the changes in mean sea level.

The subtraction of the tidal signal does not significantly change the above results in respect of the $99.9 \%$ percentile except in the Adriatic (Fig. 7d, e, f) where the $99.9 \%$ correlations with the winter NAO in the Adriatic Sea are much smaller than the correlations between the NAO index and the 99.9\% percentile of the observations.

The correlations of the NAO with the $99.9 \%$ percentile from the model sea level do not replicate the correlation 
found between the NAO and the observations. Thus only in a few stations in the winter the correlation is statistically significant (Fig. 7g). By contrast for the 50\% percentile significant negative correlation with the NAO is found for all seasons for stations at the Atlantic and the western Mediterranean (except Ceuta in the summer) (Fig. 7h). The $99.9 \%-50 \%$ is not statistically significantly correlated with the NAO. In some of the stations the significant correlation of the NAO with the $50 \%$ comes through as positive correlation of the $99.9 \%-$ $50 \%$ with the NAO. When the model data are subtracted from the tidal residuals most correlations with the NAO and the MOI become statistically insignificant at the $99.9 \%$, the $50 \%$ percentiles and the $99.9 \%-50 \%$ (not shown). Exceptions are the winter and autumn values of the 50\% percentile at Split and Dubrovnik when correlated with the MOI.

The same patterns but with higher correlations are found if the (inverted) Mediterranean Oscillation Index (MOI) is used instead of the NAO (Fig. 8). The MOI used here comes from Suselj et al. (2008). Tsimplis and Shaw (2008) have identified that mean sea level is better correlated with the (inversed) MOI rather than the NAO but here this better correlation is shown to be present in the $99.9 \%$ too, especially during autumn. However, again only a few correlation values remain statistical significant after the deduction of the median value (Fig. 8c, f, i).

The correlation of the sea level extremes with the large scale atmospheric patterns indicate that the atmospheric contribution causes most of the observed extremes and their changes Moreover these changes are linked with changes in the $50 \%$ percentile. The correlation of the NAO and the MOI is stronger for the $50 \%$ for the model values rather than the observations, an expected result probably because the noise level is much lower in the model. However, with respect to the $99.9 \%$ percentile the correlation with the NAO is stronger with the observations than with the model while the opposite is true for the MOI. We do not understand the reason for this.

\section{Summary and conclusions}

An extensive dataset of hourly sea level values from tide gauges and the output of a barotropic model have been analysed in respect of seasonal extreme values. Significant spatial variability in the observed maxima is identified in all seasons. In respect of the Atlantic stations this is primarily due to the varying tidal signal. When the tidal signal is removed most of the Atlantic stations show maxima of less than $90 \mathrm{~cm}$ occurring in winter or autumn and maxima in spring and summer lower than $60 \mathrm{~cm}$. The wind and atmospheric forcing contributes, according to the barotropic model used, about $50 \mathrm{~cm}$ in the winter maxima and between $20-40 \mathrm{~cm}$ in the maxima of the other seasons.

In the western Mediterranean Sea the maxima in the observed values are less than $50 \mathrm{~cm}$, except near the Strait of Gibraltar where they reach values of round $90 \mathrm{~cm}$. Direct atmospheric forcing contributes significantly in the maxima and in several stations its contribution is around $45 \mathrm{~cm}$ during winter and between 10-20 $\mathrm{cm}$ during summer.

The Adriatic Sea provides the most interesting area for the spatial variability of sea level maxima with the northernmost stations showing the largest maxima. This behaviour is partly due to the direct atmospheric forcing contribution which also shows significant increases at the northern stations of the Adriatic. It is also well established that the tidal signal is increasing significantly at the northern parts of the Adriatic basin (Tsimplis et al., 1995).

The time series corrected for the tidal signal and for the direct atmospheric forcing contribution through the use of the barotropic model show a reduction in the size of the extremes in all seasons. However in the north of the Adriatic Sea the same spatial pattern exists and the extremes in the residual still increase towards the north part of the basin. Sea level extremes in the northern Adriatic are affected by a resonant oscillation of around $21.5 \mathrm{~h}$ excited by the local wind field (Cerovecki et al., 1997; Raicich, 1999; Vilibic, 2006). If the barotropic model of the direct atmospheric effects was successful in modeling the atmospherically driven sea level component then the atmospherically corrected values would not have the increased values towards the northern Adriatic. Thus it is our view that the model does not represent the extreme values with sufficient accuracy either because the bathymetry in the model is not capable of creating the resonance or because the local wind field is not represented accurately enough. The latter problem is a general problem for models in the area (Wakelin and Proctor, 2002) but the persistence of the problem with the model used in this case means that the introduction of atmospheric downscaling is not capable of representing the local winds in the Adriatic.

Trends in the $99.9 \%$ percentiles are found at various sea level records for the winter and the autumn seasons. However the trends in the $99.9 \%-50 \%$ percentile are not significant. This suggests that the trends in the $99.9 \%$ percentile are in line with mean sea level changes. The North Atlantic Oscillation Index and the Mediterranean Oscillation Index are well correlated with the changes in the $99.9 \%$ winter values in the Atlantic, western Mediterranean and the Adriatic stations and, in the Atlantic and western Mediterranean in the autumn too. The correlation becomes insignificant when the $50 \%$ is removed.

This paper advances the conclusion of Marcos et al. (2009) that there are statistically significant trends in the annual maxima by demonstrating that they are statistically significant trends in the seasonal maxima too. In addition we have shown that the trends in the seasonal maxima differ between regions. The annual maxima trends are primarily determined by autumn and winter values. Furthermore this paper advances the Marcos et al. (2009) conclusion that the trends in extremes as well as the correlations with atmospheric patterns is removed when the $50 \%$ percentile is removed. We have shown that the same is true for the seasonal extremes. 
Thus, no seasonal changes in extremes in addition to those in the median are detectable. Furthermore, we have mapped the spatial patterns of seasonal extremes for the Mediterranean and the Atlantic coasts of the Iberian peninsula.

The results of this work will contribute in assessing future changes in sea level extremes in models. This work provides guidance on the seasonal and spatial patterns of extremes in the Mediterranean over the past decades. Of course significant gaps that exist in the observational records may partly bias the results. However it is arguable that the seasonal and spatial patterns of models that include the sea level parameter need to be matched, even if only in broad terms, to the results presented here. In addition the seasonal patterns emerging indicate that future changes must also be assessed on the basis of seasonal analysis in order to be able to identify whether the changes in extremes will be seasonally biased.

Acknowledgements. This work was performed as part of the EC program CIRCE. We are grateful to Marta Marcos for her assistance.

Edited by: U. Ulbrich

Reviewed by: three anonymous referees

\section{References}

Barbosa, S. M.: Quantile trends in Baltic sea level, Geophys. Res. Lett., 35, L22704, doi:10.1029/2008GL035182, 2008.

Cazenave, A., Bonnefond, P., Mercier, F., Dominh, K., and Toumazou, V.: Sea level variations in the Mediterranean Sea and Black Sea from satellite altimetry and tide gauges, Global Planet. Change, 34, 59-86, 2002.

Cazenave, A., Cabanes, C., Dominh, K., and Mangiarotti, S.: Recent Sea Level Change in the Mediterranean Sea Revealed by Topex/Poseidon Satellite Altimetry, Geophys. Res. Lett., 28, 1607-1610, 2001.

Cerovecki, I., Orlic, M., and Hendershott, M. C.:, Adriatic seiche decay and energy loss to the Mediterranean, Deep-Sea Res., PART I-OCEANOGRAPHIC RESEARCH PAPERS, 44(12), 2007-2029, 1997.

Coles, S.: An introduction to statistical modeling of ExtremeValues., Springer-Verlag London Limited., 208 pp., 2001.

Fenoglio-Marc, L.: Long-term sea level change in the Mediterranean Sea from multi-satellite altimetry and tide gauges, Phys. Chem. Earth, 27, 1419-1431, 2002.

García-Sotillo, M., Ratsimandresy, A. W., Carretero, J. C., Bentamy, A., Valero, F., and González-Rouco, F.: A high-resolution 44-year atmospheric hindcast for the Mediterranean Basin: contribution to the regional improvement of global reanalysis, Clim. Dynam., 25(2-3), 219-236, doi:10.1007/s00382-005-0030-7, 2005.

Garrett, C. and Majaess, F.: Noisostatic response of sea level to atmospheric pressure in the Eastern Mediterranean, J. Phys. Oceanogr., 14, 656-665, doi:10.1175/1520-0485, 1984.

Gomis, D., Tsimplis, M. N., Martin-Miguez, B., Ratsimandresy, A. W., Garcia-Lafuente, J., and Josey, S. A.: Mediterranean Sea level and barotropic flow through the Strait of Gibraltar for the period 1958-2001 and reconstructed since 1659, J. Geophys. Res., 111(C11), C11005, doi:10.1029/2005JC003186, 2006.

Katz, R. W. and Brown, B. G.: Extreme events in a changing climate:Variability is more important than averages, Clim. Change, 21, 289-302, 1992.

Lionello, P., Mufato, R., and Tomasin, A.: Sensitivity of free and forced oscillations of the Adriatic Sea to sea level rise, Climate Res., 29(1), 23-39, 2005.

Marcos, M. and Tsimplis, M. N.: Variations of the seasonal sea level cycle in southern Europe, J. Geophys. Res., 112(C12), C12011, doi:10.1029/2006JC004049, 2007.

Marcos, M. and Tsimplis, M. N.: Coastal Trends in Southern Europe, Geophys. J. Int., 175(1), 70-82, 2008.

Marcos, M., Tsimplis, M. N., and Shaw, A. G. P.: Sea level extremes in Southern Europe, J. Geophys. Res., 114, C01007, doi:10.1029/2008JC004912, 2009.

Monserrat, S., Vilibić, I., and Rabinovich, A. B.: Meteotsunamis: atmospherically induced destructive ocean waves in the tsunami frequency band, Nat. Hazards Earth Syst. Sci., 6, 1035-1051, doi:10.5194/nhess-6-1035-2006, 2006.

Orlić, M., Kuzmić, M., and Pasarić, Z.: Response of the Adriatic Sea to the bora and sirocco forcing, Cont. Shelf Res., 14, 91116, 1994.

Pascual, A., Marcos, M., and Gomis, D.: Comparing the sea level response to pressure and wind forcing of two barotropic models: Validation with tide gauge and altimetry data, J. Geophys. Res., 113, C07011, doi:10.1029/2007JC0044, 2008.

Pawlowicz, R., Beardsley, B., and Lentz, S.: Classical Tidal Harmonic Analysis Including Error Estimates in MATLAB using T_TIDE, Comput. Geosciences, 28(8), 929-937, 2002.

Pirazzoli, P. A. and Tomasin, A.: Recent abatement of easterly winds in the Northern Adriatic, Int. J. Climatol., 19, 1205-1219, 1999.

Pirazzoli, P. A. and Tomasin, A.: Recent evolution of surge-related events in the northern Adriatic area, J. Coast. Res., 18(3), 537554, 2002.

Pirazzoli, P. A. and Tomasin, A.: Return time of extreme sea levels in the central Mediterranean area, Bollettino Geofisico, a. XXXI, n. 1-4 gennaio-dicembre 2008, 19-33, 2002.

Raicich, F.: A case study of the Adriatic seiches (December 1997), Nuovo Cimento Della Societa Italiana Di Fisica C-Geophysics and Space Physics, 22, 715, 1999.

Raicich, F.: Recent evolution of sea-level extremes at Trieste (Northern Adriatic), Cont. Shelf Res., 23, 225-235, doi:10.1016/S0278-4343(02)00224-8, 2003.

Ratsimandresy, A. W., Sotillo, M. G., Carretero Albiach, J. C., Alvarez-Fanul, E., and Hajji, H.: A 44-year high-resolution ocean and atmospheric hindcast for the Mediterranean Basin developed within the HIPOCAS Project, Coastal Engineering, 55(11), 827-842, doi:10.1016/j.coastaleng.2008.02.025, 2008.

Suselj, K., Tsimplis, M. N., and Bergant, K.: Is the Mediterranean Sea surface height variability predictable?, Phys. Chem. Earth, 33, 225-238, 2008.

Trenberth, K. E. and Fasullo, J.: Water and energy budgets of hurricanes and implications for climate change. J. Geophys. Res. (Atmosphere), 112, D23107, doi:10.1029/2006JD008304, 2007.

Tsimplis, M. N. and Woodworth, P. L.: The Global Distribution Of The Seasonal Sea-Level Cycle Calculated From Coastal TideGauge Data, J. Geophys. Res., 99(C8), 16031-16039, 1994. 
Tsimplis, M. N., Proctor, R., and Flather, R. A.: A two-dimensional tidal model for the Mediterranean Sea, J. Geophys. Res., 100(C8), 16223-16239, 1995.

Tsimplis, M. N.: Tides and sea-level variability at the Strait of Euripus. Estuarine, Coast. Shelf Sci., 44, 91-101, 1997.

Tsimplis, M. N. and Blackman, D.: Extreme sea-level distribution and return periods in the Aegean and the Ionian Seas, Estuarine, Coast. Shelf Sci., 44, 79-89, 1997.

Tsimplis, M. N. and Spencer, N. E.: Collection and analysis of monthly mean sea level data in the Mediterranean and the Black Seas, J. Coastal Res., 13(2), 534-544, 1997.

Tsimplis, M. N., Woolf, D. K., Osborn, T. J., Wakelin, S., Wolf, J., Flather, R., Shaw, A. G. P., Woodworth, P., Challenor, P., Blackman, D., Pert, F., Yan, Z., and Jevrejeva, S.: Towards a vulnerability assessment of the UK and northern European coasts: the role of regional climate variability, Phil. Trans. Roy. Soc. A, 363, 1329-1358, 2005a.

Tsimplis, M. N., Álvarez-Fanjul, E., Gomis, D., Fenoglio-Marc, L., and Pérez, B.: Mediterranean Sea level trends: Atmospheric pressure and wind contribution, Geophys. Res. Lett., 32, L20602, doi:10.1029/2005GL023867, 2005b.

Tsimplis, M. N. and Shaw, A. G. P.: The forcing of mean sea level variability around Europe, Global Planet. Change, 63, 196-202, 2008.

Tsimplis, M. N., Marcos, M., Perez, B., Challenor, P., GarciaFernandez, M. J., and Raicich, F.: On the effect of the sampling frequency of sea level measurements on return period estimate of extremes-Southern European examples, Cont. Shelf Res., 29, 2214-2221, 2009.

Ullmann, A., Pirazzoli, P. A., and Tomasin, A.: Sea surges in Camargue: Trends over the 20th century, Cont. Shelf Res., 27, 922934, 2007.

Ullmann, A., Pirazzoli, P. A., and Moron, V.: Surges around the Gulf of Lions and atmospheric conditions, Global Planet. Change, 63, 203-214, 2008.
Vilibić, I.: A climatological study of the unidodal free oscillation in the Adriatic Sea, Acta Adriatica, 41, 89-102, 2000.

Vilibić, I., Domijan, N., Orlić, M., Leder, N., and Pasarić, M.: Resonant coupling of a traveling air pressure disturbance with the east Adriatic coastal waters, J. Geophys. Res., 109, C10001, doi:10.1029/2004JC002279, 2004.

Vilibić, I., Domijan, N., Orlić, M., Leder, N., and Pasarić, M.: Resonant coupling of a traveling air pressure disturbance with the east Adriatic coastal waters, J. Geophys. Res., 109, C10001, doi:10.1029/2004JC002279, 2004.

Vilibić, I.: The role of the fundamental seiche in the Adriatic coastal floods, Cont., Shelf Res., 26(2), 206-216, 2006.

Wakelin, S. L., Proctor, R., Preller, R., and Posey, P.: The impact of meteorological data variability on modelling storm surges in the Adriatic Sea, Proc. EGS Plinius Conferenc held in Maratea, Italy, 497-508, 1999.

Wakelin, S. L. and Proctor, R.: The impact of meteorology on modelling storm surges in the Adriatic Sea, Global Planet. Change, 34, 97-119, 2002.

Weisse, R. and von Storch, H.: Marine Climate and Climate Change, Praxis Publishing Ltd, UK, 2010.

Wolf, J. and Woolf, D. K.: Waves and Climate Change in the North-East Atlantic, Geophys. Res. Lett., 33(6), L06604, doi:10.1029/2005GL025113, 2006.

Woodworth, P. L. and Blackman, D. L.: Changes in high waters at Liverpool since 1768, Int. J. Climatology, 22, 697-714, 2002.

Woodworth, P. L. and Blackman, D. L.: Evidence for systematic changes in extreme high waters since the Mid-1970s, J. Climate, 17, 1190-1197, 2004.

Woodworth, P. L., Flather, R. A., Williams, J. A., Wakelin, S. L., and Jevrejeva, S.: The dependence of UK extreme sea levels and storm surges on the North Atlantic Oscillation, Cont. Shelf Res., 27, 935-946, 2007. 